\title{
Impact of revised thermal stability on pollutant transport time in a deep reservoir
}

\author{
Binbin $\mathrm{Wu}^{\mathrm{a}}$, Guoqiang Wang ${ }^{\mathrm{a}, *}$, Hong Jiang ${ }^{\mathrm{b}}$, Jingfu Wang ${ }^{\mathrm{c}}$, Changming Liu ${ }^{\mathrm{a}, \mathrm{d}}$ \\ ${ }^{a}$ College of Water Sciences, Beijing Normal University, Beijing 100875, China \\ b Nanjing Institute of Environmental Sciences, Ministry of Environment Protection, Nanjing 210042, China \\ ' State Key Laboratory of Environmental Geochemistry, Institute of Geochemistry, Chinese Academy of Sciences, Guiyang 550002, China \\ ${ }^{\mathrm{d}}$ Institute of Geographical Sciences and Natural Resources Research, Chinese Academy of Sciences, Beijing 100101, China
}

\section{A R T I C L E I N F O}

\section{Article history:}

Received 1 December 2015

Received in revised form 14 February 2016

Accepted 17 February 2016

Available online 24 February 2016

This manuscript was handled by Geoff

Syme, Editor-in-Chief

\section{Keywords:}

Thermal stratification

Revised Schmidt stability

Water age

Deep reservoir

Three-dimensional model

\begin{abstract}
S U M M A R Y
Thermal stability (Schmidt stability) and water age, which are significantly related to water quality and algae bloom in deep reservoirs, are two crucial indicators of stratification strength and pollutant transport time, respectively. Here, the original Schmidt stability, which was derived from a onedimensional assumption, was theoretically extended to a three-dimensional water body. In addition, a three-dimensional model was verified for the case study of Hongfeng Reservoir in China based on data from 2009 and 2010. Although the revised stability was similar to the original stability of Hongfeng Reservoir, which occurred at a relatively low level, the greater stratification in other deep water bodies would enhance their difference. Air temperature and water depth were the most important factors of the temporal variation in stability and the spatial variation in stability, respectively. The pollutant transport processes in the Hongfeng Reservoir was very complex with alternate appearances of overflow, interflow and underflow, depending on the season. The spatial water age was primarily determined by the morphometry and the inflow/outflow (with the highest water age in North Lake), whereas the vertical difference in the water age among the layers was primarily controlled by thermal stratification. Negative linear relationships between the average stability and the water ages of the bottom layers in three representative sites during summer were observed. Positive linear relationships between the average stability and the water ages of the surface layers were also observed. These findings enable a better understanding of the hydrodynamic and pollutant transport processes in a deep reservoir.
\end{abstract}

(c) 2016 Elsevier B.V. All rights reserved.

\section{Introduction}

Thermal regime (e.g., water temperature, thermal stratification and mixing) is crucial in controlling water quality (e.g., chemical and biological reactions, vertical exchange of dissolved and particulate materials) and ecosystem succession (e.g., cyanobacterial growth and dominance) of lakes and reservoirs (Wagner and Adrian, 2009; Jiang et al., 2010; Wang et al., 2012a; Rolland et al., 2013). The Schmidt stability, which is an important indicator of water column stability in limnology, has been extensively applied to evaluate the thermal stratification strength based on observed or simulated temperatures (Schmidt, 1928; Idso, 1973; Ferris and Burton, 1988; Winder and Schindler, 2004; Coats et al., 2006; Holzner et al., 2009; Yu et al., 2010; Minns et al.,

\footnotetext{
* Corresponding author at: College of Water Sciences, Beijing Normal University, Xinjiekouwai Street 19, Haidian, Beijing 100875, China. Tel.: +86 105880 2736; fax: +86105880 7814 .

E-mail address: wanggq@bnu.edu.cn (G. Wang).
}

2011; Read et al., 2011; Vincon-Leite et al., 2014; Ito and Momii, 2015). The definition of Schmidt stability was proposed by Schmidt (1928) and subsequently improved by Idso (1973). It refers to the mechanical work that is required to transform a thermally stratified water column into an isothermal state with adiabatic mixing. A free tool named Lake Analyzer (http:// lakeanalyzer.gleon.org/), which can be employed to calculate the indicators of stratification and mixing (including the Schmidt stability), was recently provided by Read et al. (2011). However, the Schmidt stability is restricted by its one-dimensional assumption of a water body; the deepest site is commonly employed to represent the vertical temperature gradient (Straile et al., 2010; Nõges et al., 2011; Read et al., 2011; Rolland et al., 2013). The traditionally one-dimensional assumption simplifies both the initial stratification state and the final isothermal state of a three-dimensional water body for Schmidt stability calculations. This traditional treatment may be suitable for long-term thermal stratification variation studies (Ambrosetti and Barbanti, 2002; Vincon-Leite 
et al., 2014; Ito and Momii, 2015; Valerio et al., 2015). However, it is inadequate for specific studies of water bodies with large areas, for which horizontal heterogeneity cannot be disregarded, particularly for reservoirs with relatively large inflow/outflow and short water residence time. Three-dimensional water temperature distribution can be achieved by numerical modeling. A method for calculating the Schmidt stability, which considers spatial heterogeneity based on three-dimensional water temperature, is needed to precisely and profoundly analyze the characteristics of thermal stratification.

Water exchange and pollutant transport process are significantly associated with water quality, algae growth and phytoplankton distribution, particularly for reservoirs (Straskraba et al., 1999; Rolland et al., 2013). Water age, which is defined as "the time that has elapsed since the particle under consideration left the region in which its age is prescribed as being zero" (Delhez et al., 1999), is a useful indicator for the temporal and spatial quantification of the transport time of pollutants (Takeoka, 1984; Boynton et al., 1995; Delhez et al., 1999; Shen and Wang, 2007; Li et al., 2011). The concept of water age has been extensively applied in coastal water areas with intense water exchange, which is induced by tides and wind (Deleersnijder et al., 2001; Liu and Huang, 2009; Liu et al., 2012), and lakes and reservoirs with intense water movement, which is induced by human regulations (Li et al., 2011; Shen et al., 2011; Wu et al., 2013). These studies also explored the dominant controlling factors of water age, such as the inflow/outflow and wind. Water age was also employed as a hydrodynamic indicator to predict water quality (e.g., nutrients) and algae (chlorophyll-a) (Hein et al., 2004; Lucas et al., 2009).

The pollutant transport process in a deep reservoir is highly influenced by thermal stratification, especially when the contaminated inflow acts as interflow (Ahlfeld et al., 2003; Zhang et al., 2015). An inverse relationship between thermal stratification (indicated by stratification number, vertical temperature difference or buoyancy frequency) and interflow travel time (defined by a certain percentage of tracer concentration) has been determined by analytical analyses, laboratory experiments or numerical simulations by many researchers (Gu et al., 1996; Gu and Chung, 1998, 2003; Ahlfeld et al., 2003; Zhang et al., 2015). Due to the difficulty of calculating the transport time at any site, few studies have addressed the thermal stratification effect on the transport process at different depths in a reservoir with complex flow patterns. This problem can be solved using the concept of water age. Thus, the objective of this study is to investigate the impact of thermal stratification (based on the revised thermal stability) on pollutant transport time (represented by water age) in a deep reservoir. The sub-objectives are as follows: (1) to extend the original Schmidt stability for the theoretical application of a threedimensional water body; (2) to present a numerical tool to determine the heterogeneous revised thermal stability and water age; and (3) to investigate the impact of the revised thermal stability on water age at different depths.

A case study of Hongfeng Reservoir, which is a deep drinking water reservoir in the Yunnan-Guizhou Plateau of China, was conducted. Hongfeng Reservoir is a warm monomictic water body that is characterized by thermal stratification in summer and mixing in winter (Shang et al., 2011). The hydrodynamic characteristics of Hongfeng Reservoir are very complex due to its complicated morphometry, irregular reservoir regulation and varied upstream inflows in changing climates and austere human activities. However, related studies are lacking; only two papers reported a simple vertical 2-D model for the connecting area between North Lake and South Lake in Hongfeng Reservoir in the 1990s (Chen, 1992; Chen et al., 1997). Algae bloom and dead fish (cage culture) have frequently been detected in the Hongfeng Reservoir since 1994; this severe eutrophication situation did not change until 2010 (comprehensive control began in 2008) (Guo et al., 2015). Consequently, an understanding of the thermal regime and the pollutant transport time in Hongfeng Reservoir is important for managing this valuable drinking water resource.

\section{Methods}

\subsection{Study area}

Hongfeng Reservoir, which is a typical deep plateau reservoir with an average depth of $10.52 \mathrm{~m}$ and a maximum depth of approximately $45 \mathrm{~m}$, is located approximately $28 \mathrm{~km}$ northwest of Guiyang City in Guizhou Province of Southwest China (Fig. 1). It is one of the largest artificial reservoirs in Guizhou Province; it has a water surface area of $57.2 \mathrm{~km}^{2}$ and a storage capacity of 0.59 billion $\mathrm{m}^{3}$ at a normal water level $(1240 \mathrm{~m}$, Wusong Elevation System). Hongfeng Reservoir was constructed in 1958 (completed in 1960) and was the first reservoir of seven cascade hydropower stations along the Maotiao River, which is a branch of the Wujiang River in the Yangtze River Basin. Hongfeng Reservoir consists of North Lake and South Lake and has five main inflows: two inflows into North Lake (Maiweng River and Maibao River) and three inflows into South Lake (Yangchang River, Maxian River and Houliu River). The Maotiao River is the only outlet of Hongfeng Reservoir (Fig. 1). Hongfeng Reservoir is an important drinking water source for Guiyang City, with a designed water supply of 0.40 million $\mathrm{m}^{3} /$ day. The major function of Hongfeng Reservoir has changed from electricity generation to drinking water supply since 2000; other auxiliary functions of the reservoir include flood control, irrigation, tourism and aquiculture.

\subsection{Numerical simulation}

The 3-D hydrodynamic Environmental Fluid Dynamics Code (EFDC) model was employed to simulate the hydrodynamic processes of Hongfeng Reservoir, including water level, currents, thermal regime and water age. The EFDC model is one of the most extensively applied and technically defensible hydrodynamic models in the world (Wu and Xu, 2011). It has been successfully applied for modeling the flow circulation, thermal stratification, sediment transport, water quality, and eutrophication processes in numerous rivers, reservoirs, lakes and estuaries (Hamrick, 1992; Ji et al., 2001; Zou et al., 2006; Liu and Huang, 2009; Li et al., 2011; Wu and Xu, 2011). Model details are provided in Hamrick (1992) and Craig (2011). In this study, temperatures were simulated using the surface heat exchange algorithm from CE-QUAL-W2 (Cole and Wells, 2006).

The water age is computed based on the concentration of a tracer and its age concentration. Transport equations for calculating these concentrations are expressed as (Delhez et al., 1999):

$\frac{\partial c(t, \vec{x})}{\partial t}+\nabla(u c(t, \vec{x})-K \nabla c(t, \vec{x}))+S=0$

$$
\frac{\partial \alpha(t, \vec{x})}{\partial t}+\nabla(u \alpha(t, \vec{x})-K \nabla \alpha(t, \vec{x}))=c(t, \vec{x})
$$

where $c$ is the tracer concentration, $\alpha$ is the age concentration of the tracer, $u$ is the velocity, $t$ is the time, $\vec{x}$ is a spatial coordinate, $K$ is the diffusivity tensor, and $S$ is the point source. The mean age (water age) of the tracer is calculated as

$a(t, \vec{x})=\frac{\alpha(t, \vec{x})}{c(t, \vec{x})}$

These equations can be solved with specified initial and boundary conditions in the EFDC model. 


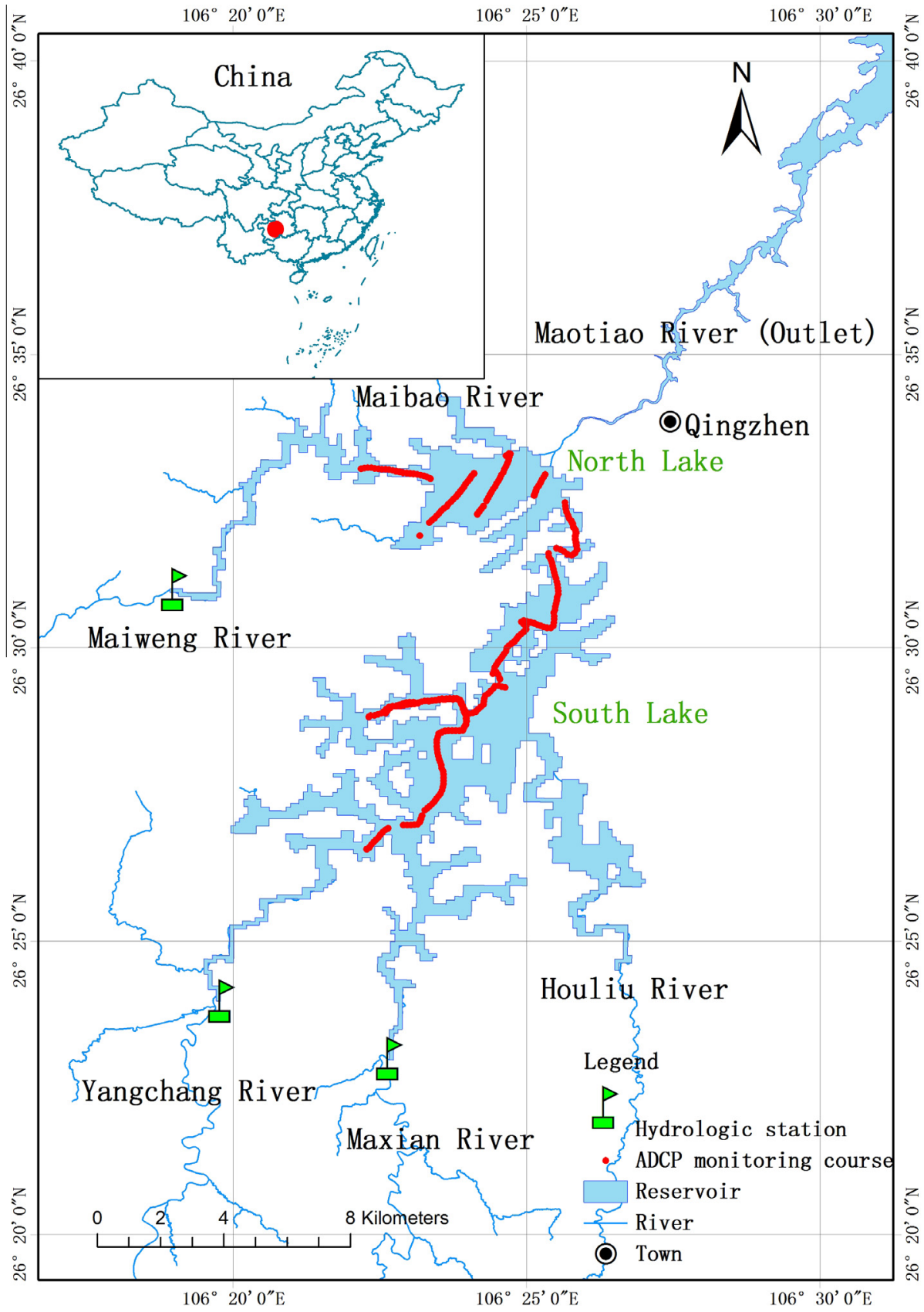

Fig. 1. Location, tributaries, hydrologic stations and ADCP monitoring course for Hongfeng Reservoir, Guizhou, China.

The modeling domain of Hongfeng Reservoir includes the entire reservoir region and the five primary tributaries to the hydrologic station or the water quality-monitoring site. Some large islands in the reservoir were treated as land in the model. Rectangular grids were constructed to set up the model, which contains 3933 active cells in the horizontal plane with a uniform grid size of $120 \times 120 \mathrm{~m}$ (Fig. 2a). A vertical sigma coordinate with an evenly distributed 20-layer system was applied to simulate the topography of the bottom. The reservoir bed and water surface elevations were utilized to determine the vertical cell thickness. The reservoir bathymetry was specified by combining a $1: 50,000$ scale topographical map with measured water depth using the Acoustic Doppler Current Profilers (ADCP); the monitoring course is shown in Fig. 1 . The bathymetry data were interpolated into the model grids. The water level-capacity curve was constructed to improve the bathymetry, and the absolute mean error (AME), root mean square error (RMS), relative root mean square error (RRMS) and the determination coefficient $\left(R^{2}\right)$ were calculated to evaluate the effects. The results showed that the final bathymetry corresponded with small AME (0.19 million $\left.\mathrm{m}^{3}\right)$, RMS (0.21 million $\left.\mathrm{m}^{3}\right)$, and RRMS (0.85\%) values and high $R^{2}$ values (near 1.00 ) (Fig. 2b). The water depth in each grid ranged from $0.5 \mathrm{~m}$ to $45.0 \mathrm{~m}$, and the average depth was approximately $11.60 \mathrm{~m}$ at a normal water level $(1240 \mathrm{~m})$; these results were generally consistent with actual measurements.

The initial conditions of surface elevation and temperature were set to average values for the first day of the simulation period. The initial flow velocity was set to zero. Daily inflows from the Maiweng River and the Yangchang River were measured at the hydrologic stations during the simulation period. For the remaining three tributaries, the daily inflows of Maxian River were calculated by hydrological modeling ( $\mathrm{Wu}$, manuscript in preparation, 2016), 
(a)
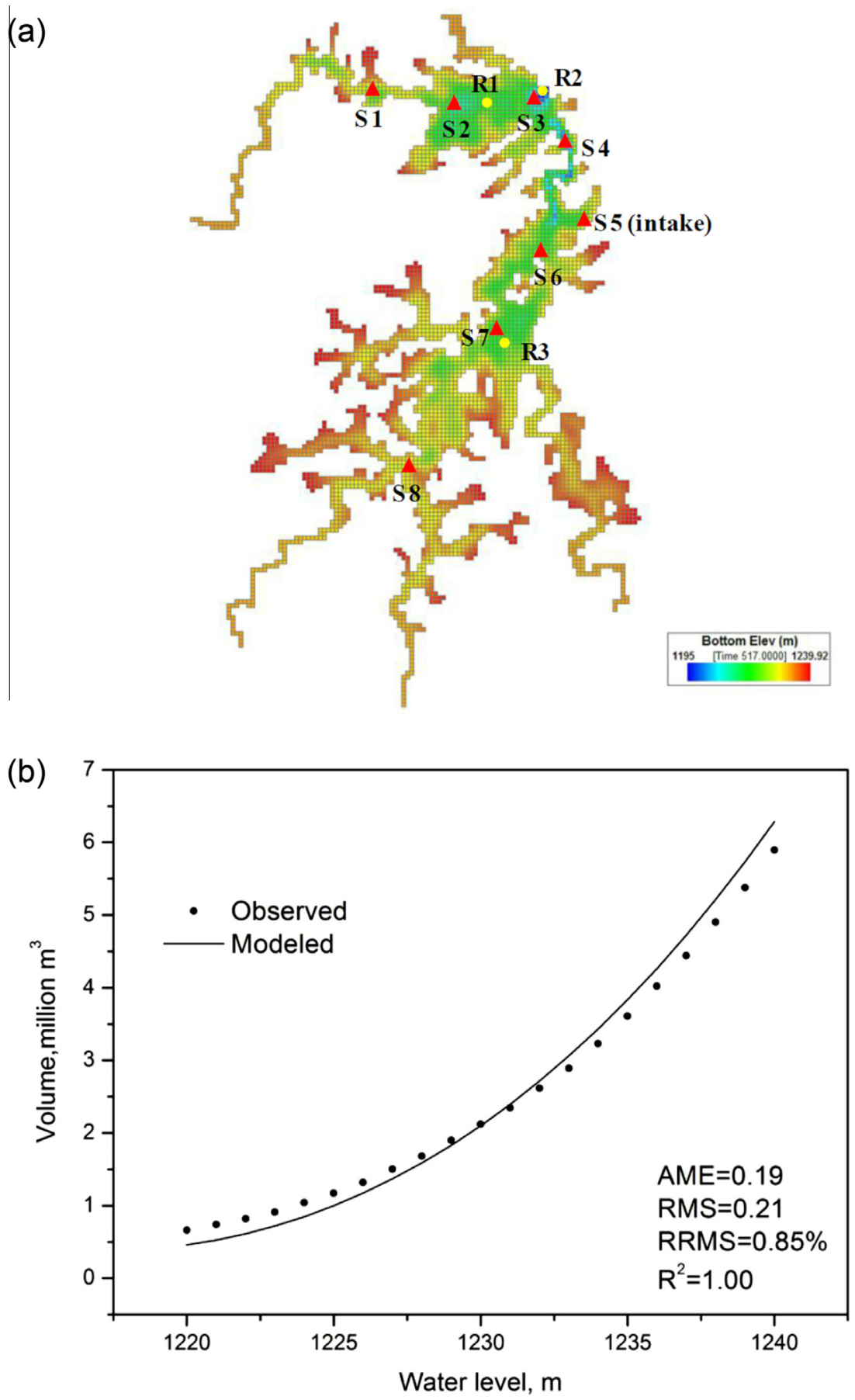

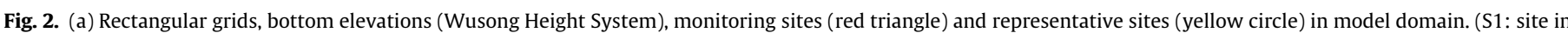

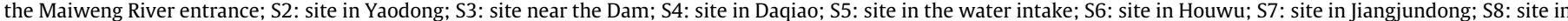

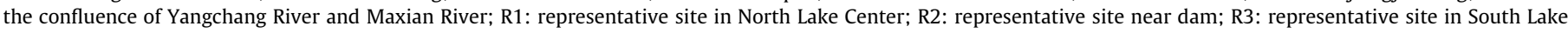

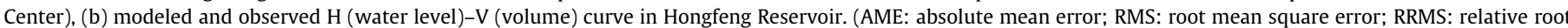

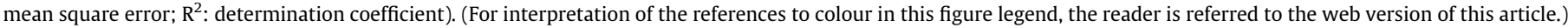

and that of Houliu River and Maibao River were determined by the drainage area ratios (Cole and Wells, 2006) due to their small watershed areas. The monthly outflows from the dam and the fixed rates for the intake pumping water from the reservoir were provided by the Administration of Hongfeng, Baihua and Aha Reservoirs. The daily outflows were calculated by the principles of water balance of the reservoir, including inflows of the reservoir, precipitation, evaporation, water withdrawal, water level and the water level-capacity curve. The monthly outflows were utilized to validate the calculated daily outflows; the results were satisfactory
$\left(R^{2}>0.85, \mathrm{Wu}\right.$, manuscript in preparation, 2016). The outflows from the dam and the water intake in the model were set according to the real positions of the power tunnel and the water intake. The daily water temperatures, which were measured at the Huangmaocun hydrologic station of the Yangchang River, were employed for all tributary entrances. The daily meteorological data, including atmospheric pressure, air temperature, relative humidity, solar radiation, cloud cover, wind speed and direction, were obtained from the Guiyang weather station (China Meteorological Data Sharing Service System, http://cdc.cma.gov.cn/home.do). Daily 
Table 1

Principal hydro-meteorological data at Hongfeng Reservoir, China.

\begin{tabular}{|c|c|c|c|c|c|c|c|c|c|c|}
\hline & $\begin{array}{l}\text { Annual } \\
\text { average } \\
\text { inflow }^{\mathrm{a}} \text {, } \\
\text { million } \mathrm{m}^{3}\end{array}$ & $\begin{array}{l}\text { Annual } \\
\text { average } \\
\text { outflow }^{\mathrm{b}} \text {, } \\
\text { million } \mathrm{m}^{3}\end{array}$ & $\begin{array}{l}\text { Annual } \\
\text { average air } \\
\text { temperature, } \\
{ }^{\circ} \mathrm{C}\end{array}$ & $\begin{array}{l}\text { Annual } \\
\text { solar } \\
\text { radiation, } \\
\mathrm{MJ} / \mathrm{m}^{2} / \mathrm{a}\end{array}$ & $\begin{array}{l}\text { Annual } \\
\text { average } \\
\text { pressure, } \\
\mathrm{hPa}\end{array}$ & $\begin{array}{l}\text { Annual } \\
\text { average } \\
\text { relative } \\
\text { humidity, \% }\end{array}$ & $\begin{array}{l}\text { Annual } \\
\text { average } \\
\text { wind } \\
\text { speed, } \mathrm{m} / \mathrm{s}\end{array}$ & $\begin{array}{l}\text { Dominant } \\
\text { wind } \\
\text { direction }\end{array}$ & $\begin{array}{l}\text { Annual } \\
\text { precipitation, } \\
\mathrm{mm}\end{array}$ & $\begin{array}{l}\text { Annual } \\
\text { evaporation, } \\
\mathrm{mm}\end{array}$ \\
\hline 2009 & 3.59 & 4.01 & 14.9 & 3977.4 & 877 & 74 & 2.5 & NE & 849.5 & 712.6 \\
\hline 2010 & 6.19 & 5.29 & 14.6 & 4055.06 & 877.3 & 77 & 2.5 & NE & 1010 & 716.3 \\
\hline $1961-2010$ & 6.12 & 6.66 & 15.16 & 3727.66 & 890.2 & 77.12 & 2.22 & NE & 1108.73 & - \\
\hline 2000-2010 & 5.67 & 5.49 & 14.55 & 3853.13 & 877.65 & 78.36 & 2.67 & NE & 1068.21 & \\
\hline Relative error $^{\mathrm{C}}$ (1961-2010) & $1.14 \%$ & $-20.57 \%$ & $-3.69 \%$ & $8.78 \%$ & $-1.45 \%$ & $-0.16 \%$ & $12.61 \%$ & & $-8.90 \%$ & \\
\hline Relative error $^{\mathrm{C}}$ (2000-2010) & $9.17 \%$ & $-3.64 \%$ & $0.34 \%$ & $5.24 \%$ & $-0.04 \%$ & $-1.74 \%$ & $-6.37 \%$ & & $-5.45 \%$ & \\
\hline
\end{tabular}

Meteorological data source: http://cdc.cma.gov.cn/home.do (except evaporation, which was measured at the hydrologic station).

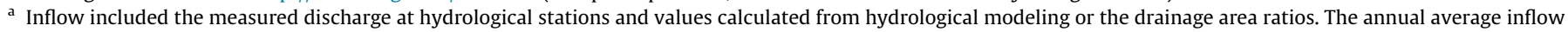
was calculated based on the time periods 1961-1983 (except 1974) and 2000-2010.

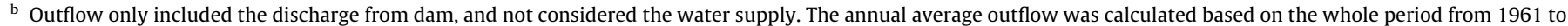
2010 (provided by the Administration of Hongfeng, Baihua and Aha Reservoirs).

c Relative error between the representative year 2010 and two long-term periods.

precipitation and evaporation data were derived from the Huangmaocun hydrologic station. For the model setup of water age, passive tracers with a unit concentration (arbitrary units) were continuously released at the entrances to the five primary tributaries and the initial conditions for the tracer and its age concentration were set to zero.

The hydrodynamic model was developed for 2009 (dry year) and 2010 (normal year) in Hongfeng Reservoir. The principal hydro-meteorological data (annual inflow/dam outflow, annual average of the mean daily air temperature/pressure/relative humidity/wind speed, dominant wind direction, and average annual solar radiation, precipitation and evaporation) for both years were compared with the corresponding data for two longterm periods-1961-2010 (since its establishment) and 20002010 (since the major function was shifted to water supply)-as shown in Table 1 . The results reveal that the absolute values of most relative errors between the hydro-meteorological data in 2010 and the 50-year means were near or less than $10 \%$ (with the exception of the annual dam outflow), and the absolute values of relative errors between 2010 and the last decade (2000-2010) were less than $10 \%$. The reduced annual dam outflow in the last decade also showed the change in the main function of the reservoir from power generation to water supply. Thus, the 2010 hydro-meteorological data generally exhibited near-average levels, and 2010 is assumed to be a representative year for the study reservoir. In this study, model verification was performed by the continuous simulation of both years and the stable results of the representative year (2010) were employed to analyze the thermal stability and water age of Hongfeng Reservoir.

\subsection{Revised thermal stability}

When we extend the original equation (Schmidt, 1928; Idso, 1973) of a one-dimensional water body to a three-dimensional water body, only the gravity direction ( $z$ direction) is considered. The work by other forces, which is needed in the horizontal direction, is disregarded because the basis of the Schmidt stability is the work of gravity force per unit surface area. The revised Schmidt stability $\left(S, \mathrm{~J} / \mathrm{m}^{2}\right)$ can be expressed as

$S=\frac{g}{A_{0}} \iiint\left(z-z^{*}\right)\left(\rho-\rho^{*}\right) d V$

$\rho=f(x, y, z)$

$\rho^{*}=\frac{1}{V} \iiint \rho d V$
$V=\iiint d V$

where $g$ is the acceleration due to gravity $\left(9.8 \mathrm{~m} / \mathrm{s}^{2}\right), A_{0}$ is the surface area of the water body $\left(\mathrm{m}^{2}\right), z$ is depth $(\mathrm{m}$, reckoned positive downward from the surface to the maximum depth), $\rho$ is the water density $\left(\mathrm{kg} / \mathrm{m}^{3}\right), \rho^{*}$ is the volume weighted mean density, $z^{*}$ is the depth at which the mean density occurs, $d V$ is the volume element and $V$ is the volume of the water body $\left(\mathrm{m}^{3}\right)$.

If we consider the final stable state to be absolutely isothermal (with a uniformed temperature) for the entire water body and employ Eqs. (6) and (7) and the following relations,

The volume centroid:

$z_{v}=\frac{1}{V} \iiint z d V$

The mass centroid:

$z_{g}=\frac{1}{V \rho^{*}} \iiint z \rho d V$

Eq. (4) can be simplified as follows:

$S=\frac{g V \rho^{*}}{A_{0}}\left(z_{g}-z_{v}\right)$

When the density distribution of the water body is uneven due to stratification, $z_{\mathrm{g}}$ is not equal to $z_{v}$ ( $z_{v}$ is fixed during mixing); when the final state (absolutely isothermal) is attained, the new $z_{g}$ is equal to $z_{v}$. Thus, Eq. (10) reflects that the Schmidt stability in this situation is the work per unit surface area by gravity force that moves the mass of the water body from the mass centroid to the volume centroid $\left(z_{g}-z_{v}\right)$. This Schmidt stability is denoted by $S_{2}$ in this paper.

The original $S$ calculation equation, which is based on a onedimensional assumption, is a special and simplified situation of the previous Eqs. (4)-(10) and can be expressed as Eq. (10). The value of $V, A_{0}$ and $z_{v}$ can be equivalent to a three-dimensional water body but the $\rho^{*}$ and $z_{g}$ would differ due to the difference in density. This traditional Schmidt stability is denoted by $S_{1}$ in this paper.

In most cases, the final stable state of a three-dimensional water body would not be absolutely isothermal for the entire water body due to different water depths. When the influence of inflow temperature is significant, the spatial difference in the horizontal direction would be distinct even without stratification in the vertical direction. Because Schmidt stability refers to conceptual mechanical work and has no relationship with heat transfer (Idso, 1973), a reasonable approach is to divide the entire water body into several parts when three-dimensional temperatures 


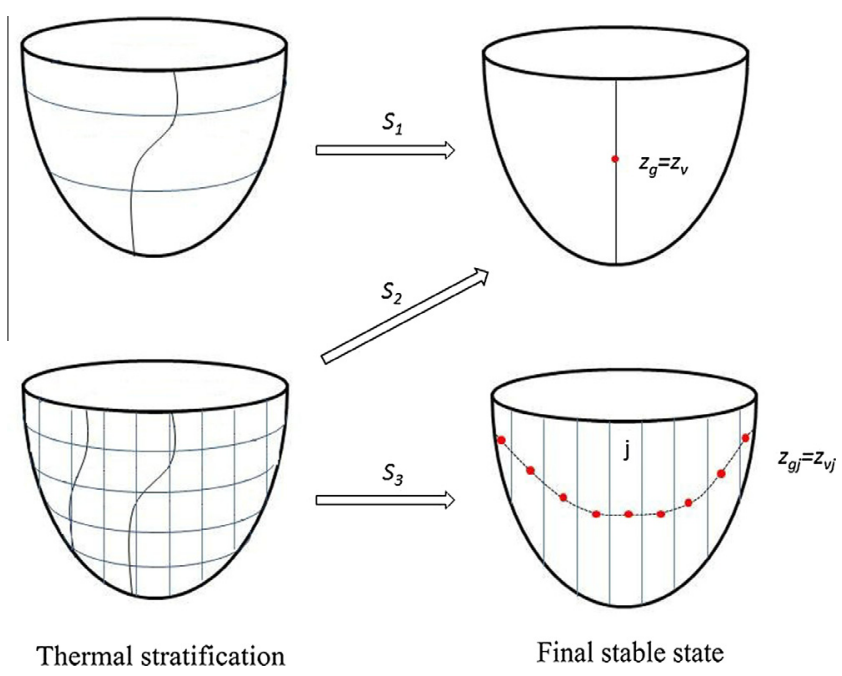

Fig. 3. The illustration of three methods calculating Schmidt stability.

are available. This method was employed for water bodies with several monitoring sites, in which the vertical temperature profile and corresponding bathymetry for each site were applied as inputs (Yu et al., 2010; Minns et al., 2011). If the entire water body is divided into parts, which is sufficiently small (e.g., grids in the hydrodynamic model), then each part/grid can be treated as an independent one-dimensional water column. The final stable state in this situation would be isothermal for each part/grid but it would not be absolutely isothermal for the entire water body. The assumed final stable state may be similar to the real situation if the parts/grids are sufficiently small. In this case, the $\rho^{*}$ and $z^{*}$ in Eq. (4) and the $z_{v}$ and $z_{g}$ in Eq. (10) varied with the part/grid and the spatial Schmidt stability for each part/grid $j$ was calculated as

$S_{j}=\frac{g}{A_{0 j}} \int_{0}^{H_{j}} A_{z j}\left(z_{j}-z_{j}^{*}\right)\left(\rho_{z j}-\rho_{j}^{*}\right) d z=\frac{g V_{j} \rho_{j}^{*}}{A_{0 j}}\left(z_{g j}-z_{v j}\right)$

where $A_{z j}$ is the area at depth $z_{j}$ for part/grid $j, \rho_{z j}$ is the water density $\left(\mathrm{kg} / \mathrm{m}^{3}\right)$ at depth $z_{j}$ for part/grid $j, H_{j}$ is the maximum depth for part/grid $j$, and the remaining variables are equivalent to the variables in Eq. (4) but for part/grid $j$.

For the entire water body, the Schmidt stability (referred to as $S_{3}$ ) is expressed as follows:

$S=\frac{1}{A_{0}} \iint S_{j} d A$

For these three methods, the Schmidt stability is zero when the water column is isothermal $\left(z_{\mathrm{g}}=z_{v}\right.$ or $\left.z_{\mathrm{gj}}=z_{v j}\right)$, is greater than zero when stratification occurs $\left(z_{g}>z_{v}\right.$ or $z_{g j}>z_{v j}$ because density increases with increasing depth), and is maximal when it is most significantly stratified. The illustration of the three methods for calculating the Schmidt stability is shown in Fig. 3.

In this study, our hydrodynamic model divided Hongfeng Reservoir into $n$ (active cells: $n \leqslant 3933$, varied with water level) rectangular grids with uniform size in the horizontal plane and $m(m=20)$ evenly distributed layers in the vertical plane. The original integral equations were modified to simple sums because the results from the hydrodynamic model did not form continuous function over the depth. Consequently, the two methods for calculating the Schmidt stability based on the three-dimensional temperatures is simplified as follows:

Spatial Schmidt stability for grid $j$ :

$S_{j}=\frac{g}{2 m}\left[2 H_{j} \sum_{i=1}^{m} z_{i j} \rho_{i j}-H_{j}^{2} \sum_{i=1}^{m} \rho_{i j}\right]$

$$
\begin{aligned}
& S_{2}=\frac{g}{2 m * n}\left[2 \sum_{j=1}^{n} H_{j}\left(\sum_{i=1}^{m} z_{i j} \rho_{i j}\right)-\frac{\sum_{j=1}^{n} H_{j}^{2} * \sum_{j}^{n} H_{j}\left(\sum_{i=1}^{m} \rho_{i j}\right)}{\sum_{j=1}^{n} H_{j}}\right] \\
& S_{3}=\frac{g}{2 m * n}\left[2 \sum_{j=1}^{n} H_{j}\left(\sum_{i=1}^{m} z_{i j} \rho_{i j}\right)-\sum_{j=1}^{n} H_{j}^{2}\left(\sum_{i=1}^{m} \rho_{i j}\right)\right]
\end{aligned}
$$

The water density is primarily determined by water temperature and secondly total suspended solid (TSS) in freshwater (Cheng and Kao, 2008; Wang et al., 2012a). The effect of TSS can be disregarded if the concentration is low (e.g., $<0.8 \mathrm{~kg} / \mathrm{m}^{3}$ ) (Yang et al., 2010). According to our monitoring data for 2009 (September), 2010 (January and October) and 2013 (June), the TSS in Hongfeng Reservoir was very low and the maximum value did not exceed $0.03 \mathrm{~kg} / \mathrm{m}^{3}$. Therefore, water density can be considered as a function of water temperature (Gill, 1982; Hamrick, 1992) in Hongfeng Reservoir.

\subsection{Numerical experiments}

To analyze the influence of thermal stability on water age, several numerical experiments were conducted based on the longterm local climate of Hongfeng Reservoir (50 years: 1961-2010, Fig. 4). The representative year (2010) was employed as the base year with an annual average air temperature of $14.6^{\circ} \mathrm{C}$, which was at the low end (Fig. 4). First, a scenario without a temperature module was designated Case 1 to eliminate the impact of thermal stratification. Then, the year 1993 with an annual average air temperature of $15.3^{\circ} \mathrm{C}$, which represented the average level of the study area (Fig. 4) and was approximately 5\% higher than the annual average air temperature in 2010, was designated Case 2. The year 1998 with an annual average air temperature of $16.3^{\circ} \mathrm{C}$, which was the highest year since 1961 (Fig. 4) and was approximately $10 \%$ higher than the annual average air temperature in 2010, was designated Case 3. Additionally, Case 4 and Case 5 with $-5 \%$ and $-10 \%$ lower annual average air temperature than that in 2010, were also conducted in order to verify the impact of thermal stratification more effectively. Although the annual average air temperatures of Case $4\left(13.9^{\circ} \mathrm{C}\right)$ and Case $5\left(13.14^{\circ} \mathrm{C}\right)$ were near or lower than the minimum temperature in the past 50 years (1961-2010, Fig. 4), extreme weather might occur during climate change. In all cases, the model inputs and parameters, with the exception of the air temperature, were equivalent to the observed data for 2010. Each model was employed to simulate $365 \mathrm{~d}$, and the initial conditions were set as the last day of 2009. For all the cases, three kinds of Schmidt stability $\left(S_{1}, S_{2}\right.$, and $\left.S_{3}\right)$ were calculated for the whole reservoir, and $S_{j}$ were calculated for three representative sites (R1: North Lake Center, R2: Dam, R3: South Lake Center, Fig. 2). Water age was also computed for those cases. Finally, the relationship between thermal stability and water age was discussed.

\section{Results and discussion}

\subsection{Model verification}

Prior to the application in the water age simulation, field data from 2009 and 2010 were employed to verify the hydrodynamic model (water level and water temperature). The main calibrated parameters included the time step, the bottom roughness height $\left(Z_{0}\right)$, the horizontal and vertical eddy viscosities and diffusivities, the wind sheltering coefficient, the wind drag coefficient and several parameters related to temperature. The adaptive time step was employed to rapidly and stably run the model. The $Z_{0}$ was set to a typical value of $0.02 \mathrm{~m}$ (HydroQual Inc., 2002; Hamrick, 


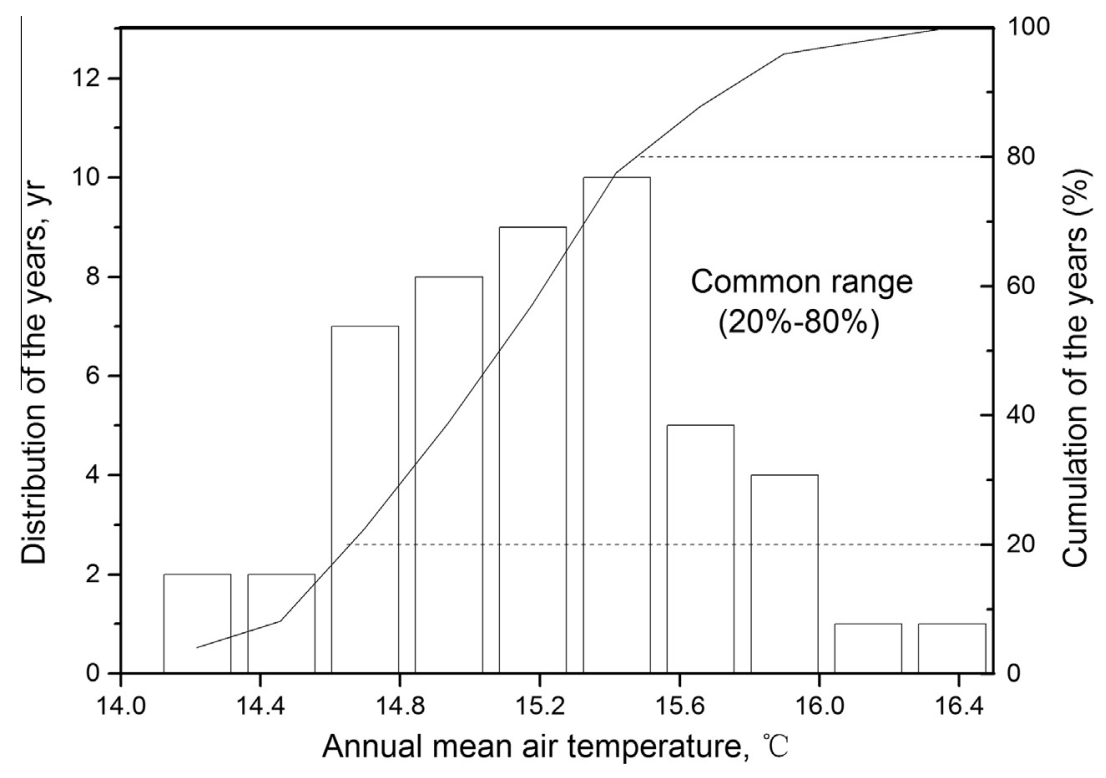

Fig. 4. Probability distribution of annual average air temperature for 50 years (1961-2010) in Guiyang weather station.

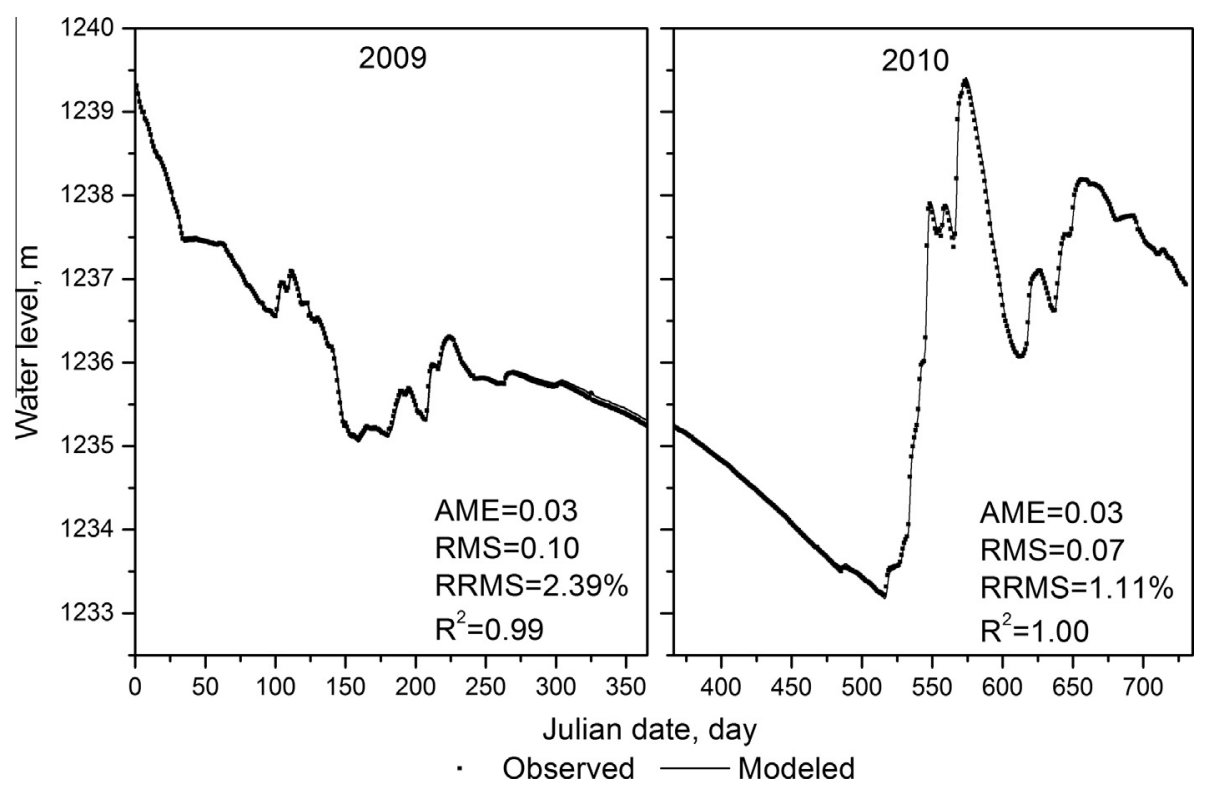

Fig. 5. Modeled and observed water levels at site S3 in 2009 and 2010.

1992). The parameters related to the Mellor and Yamada turbulence model (Mellor and Yamada, 1982) were set to the same values as the parameters employed in other hydrodynamic models, such as the Princeton Ocean Model and the Estuary, Coastal and Ocean Model (HydroQual Inc., 2002). The dimensionless viscosity parameter in the Smagorinsky (1963) formula was set to a constant value of 0.2 for the horizontal turbulence model (Berntsen, 2002). To adapt to the water level fluctuations, a moving water surface boundary was applied in the model by assigning a threshold value of the water depth to identify the dry elements $(0.5 \mathrm{~m})$ and the wetting/drying procedure of Hamrick (1994).

To quantify and assess the performance of the model, the AME, RMS, RRMS and $R^{2}$ were also applied. The water levels at site S3 near the dam (Fig. 2a) were recorded during the simulation period. Modeled and observed water levels showed reasonable agreement with both 2009 and 2010 water levels (Fig. 5), with a small AME $(\leqslant 0.03 \mathrm{~m})$, RMS $(\leqslant 0.10 \mathrm{~m})$, RRMS $(\leqslant 2.39 \%)$ and high $R^{2}(\geqslant 0.99)$.
These results demonstrated that the hydrodynamic model adequately simulated surface fluctuations caused by variations in wind, precipitation, evaporation, freshwater discharge, and water removal. The heat budget adequately reproduced the temporal and spatial variation in the reservoir water temperature. The monthly surface water temperatures at one site (S5, intake) in 2009 and seven sites (S1, S3, S4-8) in 2010 (Fig. 2a) were collected from the Guiyang Institute of Eco-Environmental Sciences. In both years, the model generally captured the seasonal changes of the surface water temperatures (Fig. 6) with acceptable AME $\left(\leqslant 1.65^{\circ} \mathrm{C}\right)$, RMS $\left(\leqslant 2.42^{\circ} \mathrm{C}\right)$, RRMS $(\leqslant 13.99 \%)$ and $R^{2}(\geqslant 0.90)$. The vertical temperatures were measured at four sites (S2, S3, S6 and S7, Fig. 2a) during the summer and winter of 2009 (Shang et al., 2011), and once-a-month vertical temperatures were measured at site S3 (Fig. 2a) in 2010. Our model results were generally consistent with the observation data with small AME (0.38 and $\left.0.92{ }^{\circ} \mathrm{C}\right)$, RMS $\left(0.51\right.$ and $\left.1.12{ }^{\circ} \mathrm{C}\right)$, RRMS (1.53\% and 6.64\%) and high 

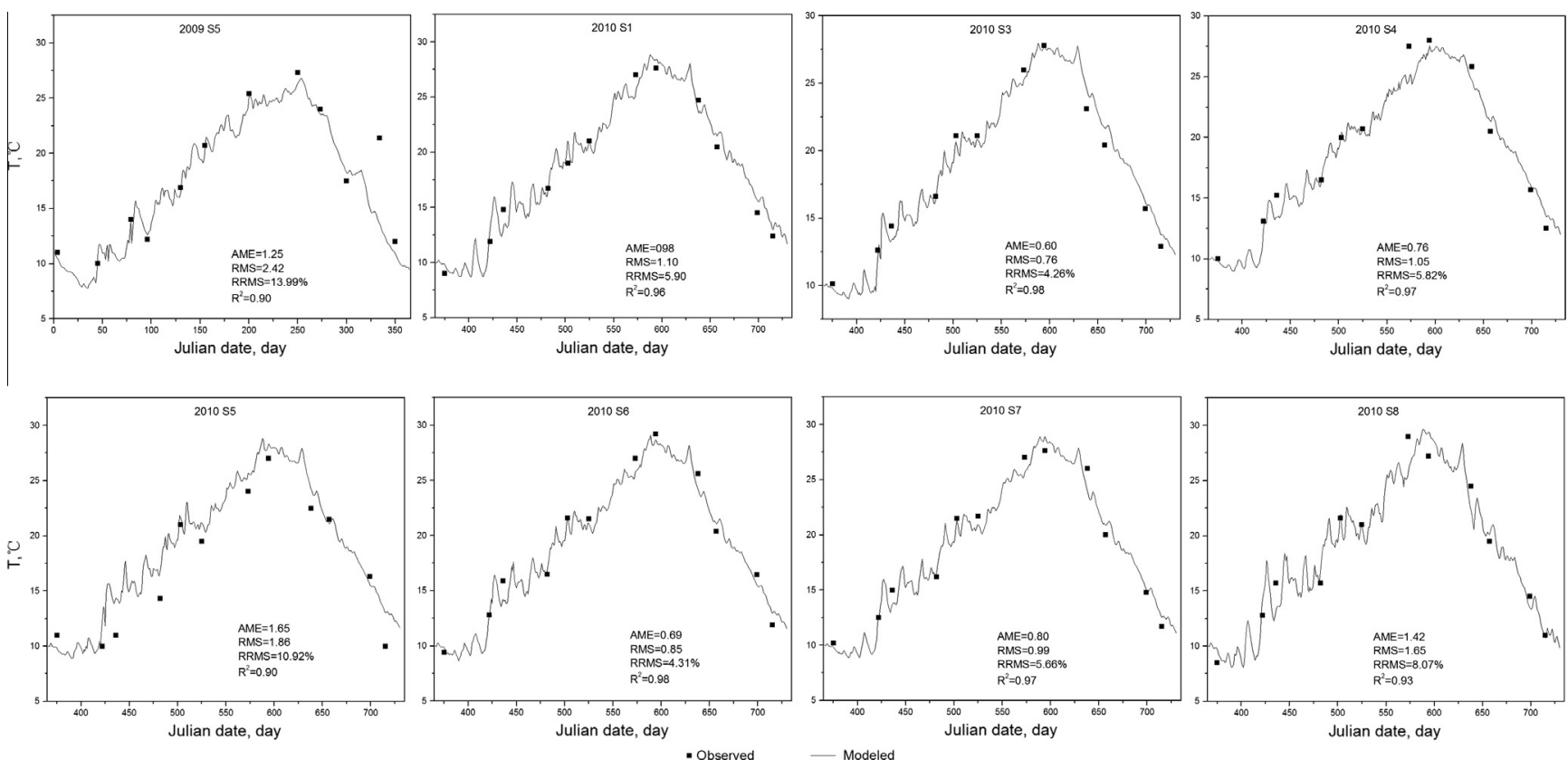

Fig. 6. Modeled and observed surface temperature at different sites in 2009 and 2010.
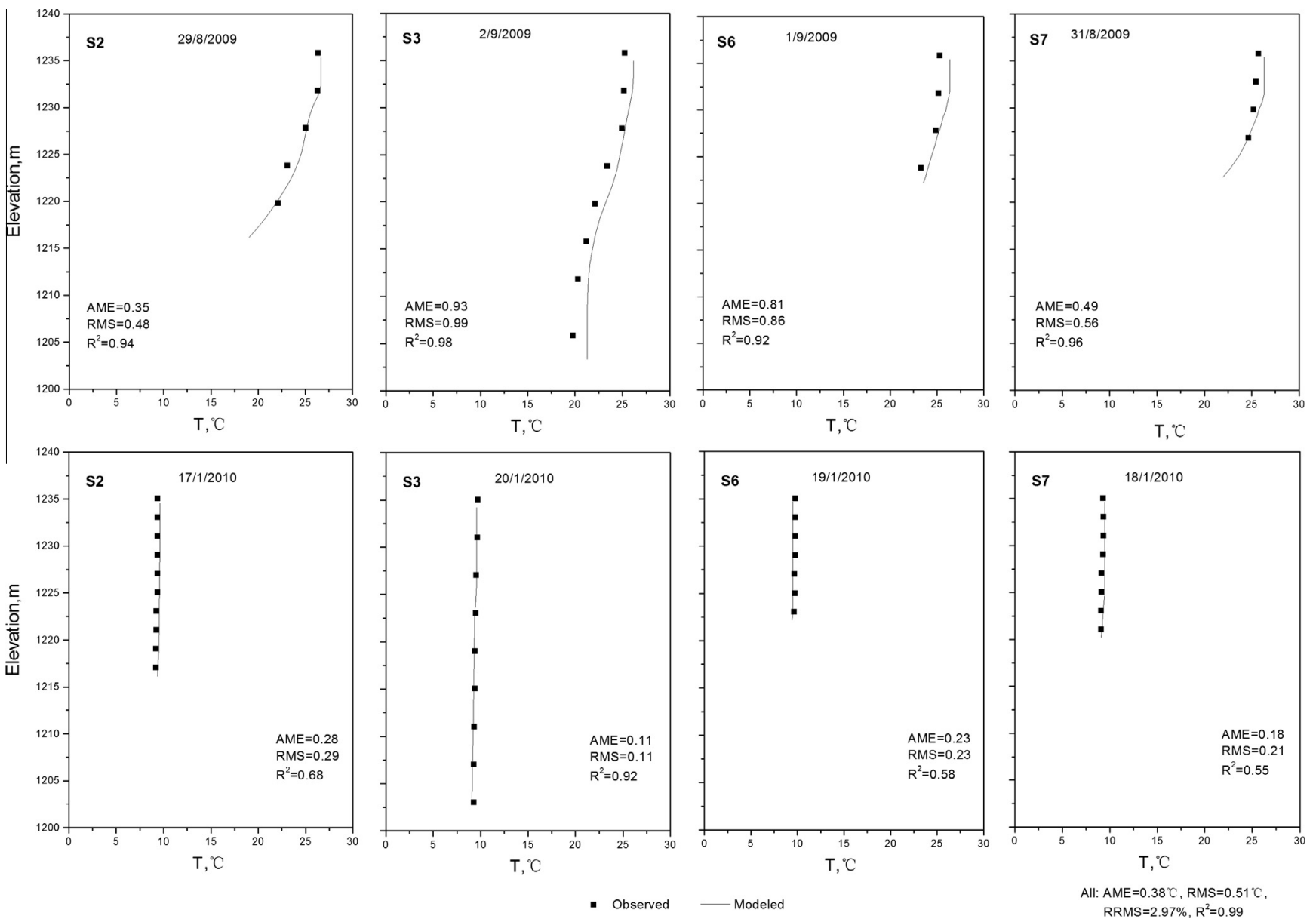

Fig. 7. Modeled and observed vertical temperature at four sites in summer and winter.

$R^{2}(0.99$ and 0.95$)$ for all four sites during summer and winter (Fig. 7) and all months for site S3 in 2010 (Fig. 8). The modeled vertical temperature generally captured the thermal stratification in spring and summer and the homogenized temperature in autumn and winter. The hydrodynamic model showed satisfactory performance and was sufficiently accurate for age simulations and 

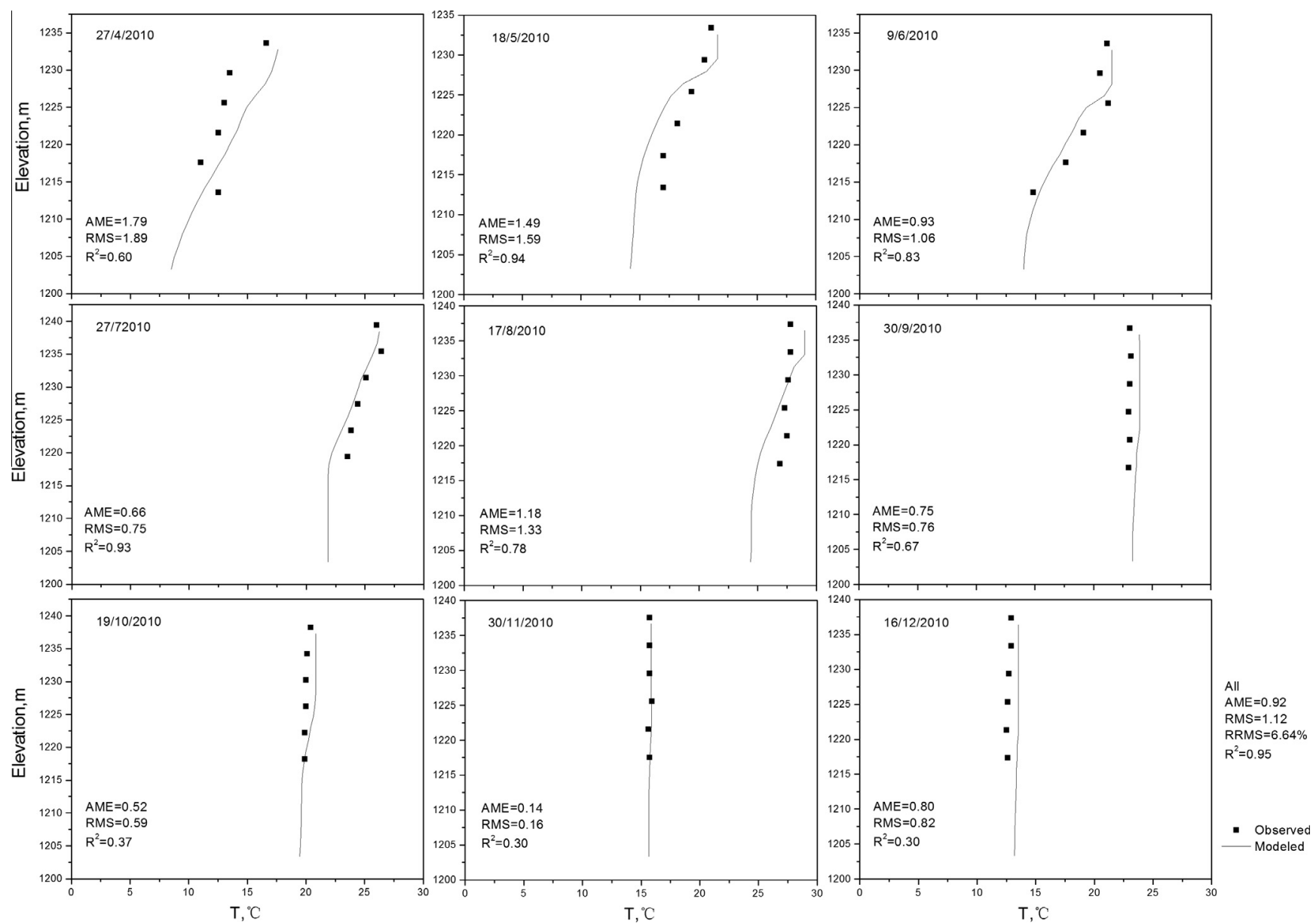

Fig. 8. Modeled and observed vertical temperature at site S3 in 2010.

understanding the hydrodynamic processes in Hongfeng Reservoir. An increased monitoring frequency and vertical monitoring resolution are needed for more accurate modeling and prediction in the future.
$S_{2}$ during stratification (because the magnitude of $\rho^{*}$ is large than $z_{g}$ ). Additionally, $S_{3}$ could be converted to $S_{2}$ when all the $z_{g j}$ points were moved to $z_{v}$ (Fig. 3), and the difference between $S_{3}$ and $S_{2}$ could be calculated as follows according to Eqs. (14) and (15):

$$
\begin{aligned}
S_{3}-S_{2} & =\frac{g}{2 m * n}\left[\frac{\sum_{j=1}^{n} H_{j}^{2} * \sum_{j=1}^{n} H_{j}\left(\sum_{i=1}^{m} \rho_{i j}\right)}{\sum_{j=1}^{n} H_{j}}-\sum_{j=1}^{n} H_{j}^{2}\left(\sum_{i=1}^{m} \rho_{i j}\right)\right] \\
& =\frac{g}{2 m * n} * \frac{H_{1} H_{2}\left(H_{1}-H_{2}\right)\left(\sum_{i=1}^{m} \rho_{i 2}-\sum_{i=1}^{m} \rho_{i 1}\right)+H_{1} H_{3}\left(H_{1}-H_{3}\right)\left(\sum_{i=1}^{m} \rho_{i 3}-\sum_{i=1}^{m} \rho_{i 1}\right)+H_{2} H_{3}\left(H_{2}-H_{3}\right)\left(\sum_{i=1}^{m} \rho_{i 3}-\sum_{i=1}^{m} \rho_{i 2}\right)+\cdots}{\sum_{j=1}^{n} H_{j}}
\end{aligned}
$$

\subsection{Revised thermal stability}

To estimate the thermal stratification characteristics in Hongfeng Reservoir, the integrated Schmidt stability for the entire reservoir $\left(S_{2}\right.$ and $\left.S_{3}\right)$ and the spatial Schmidt stability $\left(S_{j}\right)$ were calculated based on the three-dimensional simulated temperatures in this study. $S_{1}$ was also calculated using the traditional method (temperature profile for the deepest site near the dam, bathymetry data and water level) based on the Lake Analyzer program (Read et al., 2011). The results showed that $S_{2}$ was generally higher than $S_{1}$ and $S_{3}$ during the stratification period ( $p<0.01$, Fig. 9a) and that the stronger the stratification is, the larger is the difference. It is reasonable because $S_{1}$ and $S_{2}$ have similar equations and variables, and a three-dimensional consideration would decrease $\rho^{*}$ and increase $z_{g}$ during stratification, $S_{1}$ would generally be less than
If $H_{j}>H_{k}$ and thermal stratification occurs, it is generally correct that $\sum_{i=1}^{m} \rho_{i j}>\sum_{i=1}^{m} \rho_{i k}$, which yields $S_{3}-S_{2}<0\left(S_{2}>S_{3}\right)$. On the other hand, $S_{1}$ and $S_{3}$ did not exhibit a significant difference for the entire year ( $p>0.05$, Fig. 9a). The comparison of $S_{1}$ with $S_{3}$ is difficult when only the equations are considered. Compared with other lakes and reservoirs (Kling, 1988; Wang et al., 2012a), the values of the Schmidt stability in Hongfeng Reservoir were relatively low during the stratification period $\left(\mathrm{S}_{1 \max }=326.05 \mathrm{~J} / \mathrm{m}^{2}\right.$, $\left.S_{2 \max }=436.76 \mathrm{~J} / \mathrm{m}^{2}, S_{3 \max }=275.93 \mathrm{~J} / \mathrm{m}^{2}\right)$. The average state of stratification for the entire reservoir belonged to the slightly stable group in Kling (1988). This is primarily attributed to the relatively low water depth and the deep-water withdrawal for power generation.

In general, a similar temporal trend was observed for the three kinds of stability (Fig. 9a). A threshold of $49 \mathrm{~J} / \mathrm{m}^{2}$ was employed to 

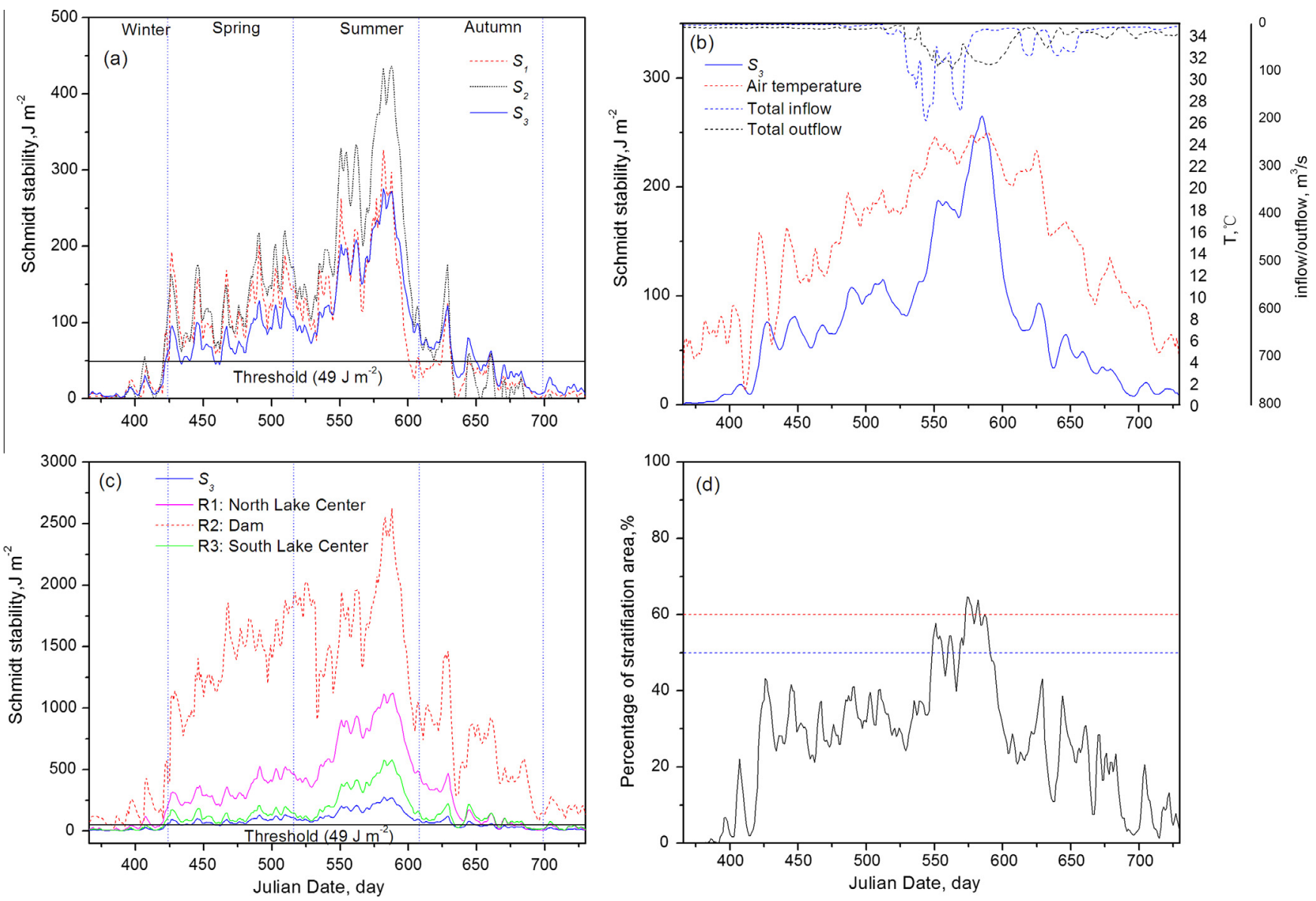

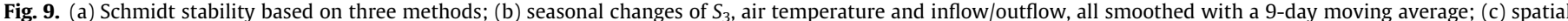
Schmidt stability $\left(S_{j}\right)$ in three representative sites; (d) time series of percentage of stratification area.

Table 2

Results of thermal stability in 2010 for Hongfeng Reservoir.

\begin{tabular}{|c|c|c|c|c|}
\hline Thermal stability & Onset of stratification & Date of maximum stability & End of stratification & Maximum stability $\left(\mathrm{J} / \mathrm{m}^{2}\right)$ \\
\hline$S_{1}$ & 25 February & 5 August & 24 August & 326.05 \\
\hline$S_{2}$ & 25 February & 11 August & 25 September & 436.76 \\
\hline$S_{3}$ & 27 February & 5 August & 26 September & 275.93 \\
\hline
\end{tabular}

estimate the onset timing of the stratification (Wang et al., 2012a; Winder and Schindler, 2004). Table 2 listed the thermal stratification characteristics for the three kinds of stability. The stratification generally began at the end of February, increased gradually, reached a maximum value at the beginning of August, then abruptly and sharply decreased, and finally disappeared and became completely mixed at the end of August for $S_{1}$ or at the end of September for $S_{2}$ and $S_{3}$ (Fig. 9a, Table 2). According to the field observation of Hongfeng Reservoir from Wang et al. (2012b), the disappearance of stratification was around 23 September in 2010, which was more closer to the results of $S_{2}$ and $S_{3}$ than that of $S_{1}$. Hence, the stability considering threedimensional temperatures for the stratification $\left(S_{2}\right.$ and $\left.S_{3}\right)$ seemed to be more accurate than the traditional one-dimensional stability $\left(S_{1}\right)$. According to results of $S_{2}$ and $S_{3}$, the duration of the stratification accounted for approximately $58.90 \%$ of 2010 . Furthermore, the stability exhibited large fluctuations, which reflects the sensitive response of thermal stratification/mixing to the variable external forces. The Pearson correlation analysis showed that three kinds of stability were all significantly related to air temperature $\left(R^{2} \geqslant 0.79, p<0.05\right)$ and high air temperature was generally associated with enhanced stratification (high stability) (Fig. 9b, only $S_{3}$ was showed for clearance). The hydrological condition (primarily inflow/outflow) was another important factor that influenced thermal stratification in addition to air temperature, which acted in a reverse manner to restrict the increasing stability, particularly in summer (Fig. 9b). These results were consistent with the findings of Wang et al. (2012a) in numerical scenarios.

For the distribution of Schmidt stability ( $S_{j}$ for each grid) in Hongfeng Reservoir, the results showed a distinct spatial heterogeneity. Three representative sites (Fig. 2a) were selected; all time series of Schmidt stability showed similar trends but significant higher values than that for the entire reservoir (Fig. 9c). The deepest site (R2, near dam) had a distinctly longer duration and stronger strength of stratification with a maximum $\left(2679.00 \mathrm{~J} / \mathrm{m}^{2}\right)$ in summer. Thus, the traditional method of treating a water body as a one-dimensional body will considerably underestimate the local stratification state. The time series of the percentage of stratification area revealed 34 days and 9 days in which the percentage of stratification area exceeded $50 \%$ and $60 \%$, respectively (Fig. 9d). The maximum value was $64.63 \%$ on July 28,2010 , when stratification occurred in most areas in the North Lake and the South Lake, 

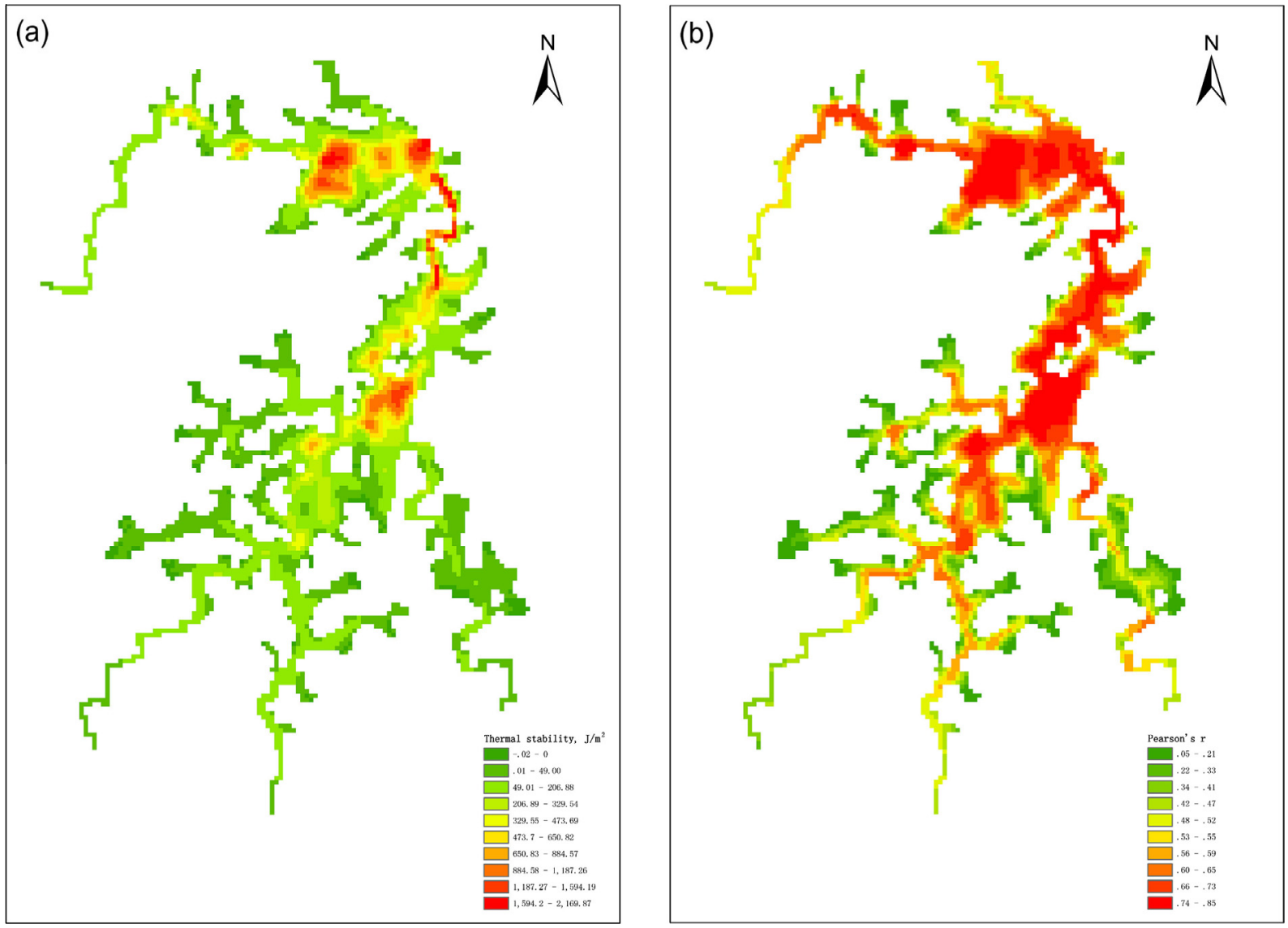

Fig. 10. Spatial distribution of (a) thermal stability $\left(S_{j}\right)$ on 28 July; (b) Pearson's $r$ for the daily thermal stability and air temperature in Hongfeng Reservoir.

especially in the deep areas (Fig. 10a). On this day, a significant positive correlation between the Schmidt stability and water depth $\left(R^{2}=0.90, p<0.05\right)$ was obtained, which implies that the bathymetry (water depth) was another controlling factor for the Schmidt stability in addition to the external forces. Besides, the spatial stability also showed high correlations with air temperature, particularly for the deep areas (Fig. 10b). Overall, the long duration and widespread thermal stratification in Hongfeng Reservoir caused anoxia and nutrient enrichment in the hypolimnion (Shang et al., 2011), which caused adverse impacts on the aquatic ecosystem.

\subsection{Water age}

Water age at any location of Hongfeng Reservoir may be utilized to represent the average elapsed time for parcel transport from the inflow entrances. The time series of water age for the surface, middle and bottom layers at three representative sites (Fig. 2a) showed a similar trend with increasing age at the beginning, a sharp decline in summer and a flat or slightly upward trend in autumn and winter (Fig. 11a-c). To ensure an adequate water supply and to maintain a certain water level, no dam discharge (no power generation) occurred from January to May in 2010 and the inflows in these months were also very low, which produced the constantly increasing age in the corresponding period. With the increasing inflows and outflow in summer, the water age gradually reduced and a sudden drop occurred in July due to the substantially increasing inflows and dam discharge. Water age generally continued to decrease in August due to the large dam discharge and became relatively stable or slightly increased in the following months. The fluctuations in water age generally kept pace with the variable inflow and outflow (Fig. 11d). For the average water age (yearly average and depth average) among the three representative sites in 2010, the North Lake Center site showed the highest value (261.51 days) and the South Lake Center had the lowest value (202.86 days). The value for the dam was 249.04 days, which was significantly higher than the residence time for the reservoir (95 days), as reported by Bai et al. (2002). However, this value is highly associated with the entrances (zero points); if the confluence of the Yangchang River and the Maxian River was selected as the zero point in South Lake, the final water age in Dam would be approximately 100 days.

The water age at different layers for the shallow areas (margin areas) showed homogeneity for the entire year in 2010 (only experienced a temporal change with external forces); however, the majority of the areas of the reservoir were sufficiently deep to exhibit the mixing and stratification features in different seasons. A similar water age was obtained for the different layers during the mixing period in winter and early spring for the three representative sites. The water age of the surface layer gradually became less than water age of the middle layer and the bottom layer in mid-spring (the beginning of stratification), which kept to summer, implying that inflow water primarily entered as a surface plume during this period. The main reason for this finding was the difference between the inflow temperature and the stratified thermal regime in the reservoir. Although the density difference existed with a higher temperature of inflow during summer, the overflow instantly changed into underflow (with a minimum water age in the bottom layer) at R2 (dam) in early summer (approximately 5 July) due to the impact of the large dam discharge (because the outlet is near the bottom). The water ages of the middle layer at R2 (dam) generally varied between the surface and the bottom layers. However, the influence of the dam discharge had a hysteresis 

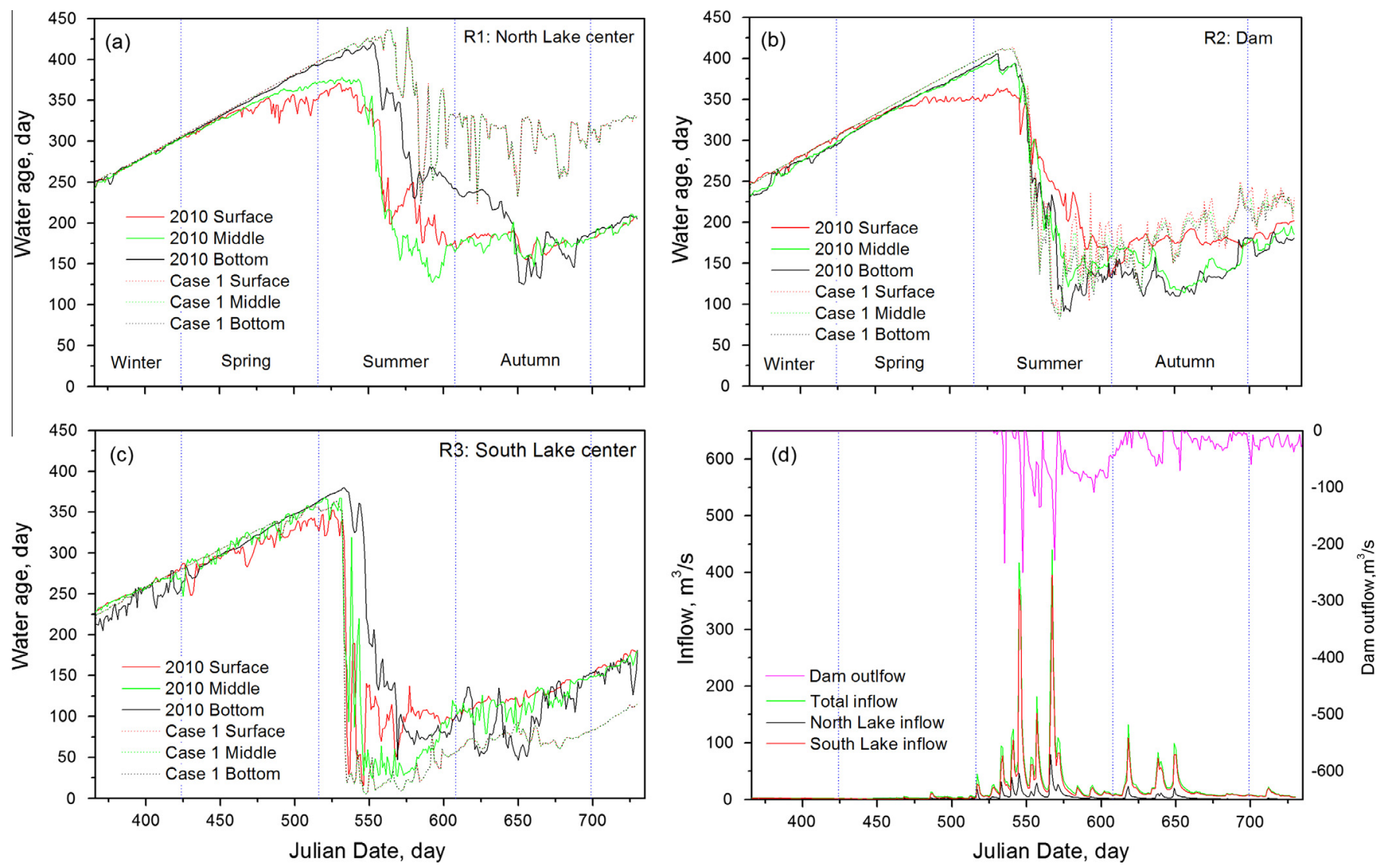

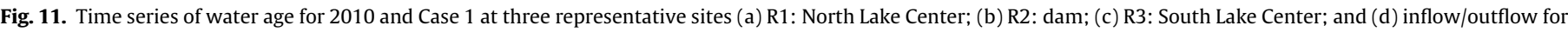
Hongfeng Reservoir

on North Lake and South Lake. The overflow dominated in the beginning of summer for both sites in the center of North Lake and South Lake (R1 and R3) and changed into interflow (with a minimum water age in the middle layer) in the middle of summer, probably due to the changed temperature difference between inflow and the stratified water. The interflow did not change into underflow until the middle of autumn for R1 (North Lake Center) and the end of the summer for R3 (South Lake Center). Subsequently, the water age for different layers was similar at R1 (North Lake Center) in winter due to the mixing. However, underflow continued to dominate at R2 (dam) and R3 (South Lake Center), which was controlled by the dam discharge during this period. These results also reflect that the dam discharge had a greater impact on South Lake than North Lake, which was reasonable because the inflow from South Lake dominated the total inflow in Hongfeng Reservoir and supplied the dam discharge (Fig. 11d), although the dam was located in North Lake. As a whole, the vertical distribution of water age was controlled by the water depth, the density difference (inflow temperature and thermal regime in the reservoir), and the dam discharge depth and quantity.

For the spatial distribution of water age in Hongfeng Reservoir, the yearly average water age of the surface, middle and bottom layers revealed a general trend with water age that gradually increased from south to north, with the exception of the entrances of the inflows (Fig. 12a-c). The highest water age was obtained in the North Lake. The regional difference in the North Lake was small, with the exception of the dam area in the bottom layer with a relatively lower age due to the influence of discharge and inflows from South Lake. Overall, South Lake exhibited river characteristics with relatively smaller water ages, whereas North Lake showed a larger number of lake characteristics with a relatively greater amount of stagnant water. The spatial distributions of water age were generally consistent with the corresponding flow circulations (yearly average, Fig. 12a-c) and followed the path of freshwater movement. The large gyre in North Lake in the surface layer and the bottom layer, as well as the small gyre in the center of South Lake in the bottom layer caused the relative higher water ages in these areas.

\subsection{Effect of thermal stratification on water age}

The above analyses of thermal stability and water age characteristics in Hongfeng Reservoir showed distinct temporal and spatial changes, which were significantly associated with morphometry, inflow (discharge and temperature)/outflow (depth and discharge), and air temperature (influence the stratified temperature in the reservoir and indirectly affect water age). The vertical distribution of water age was highly related to the thermal stratification; this finding was further proven by the results for Case 1 (without temperature module). Although the outlet was located near the bottom and the outflow was considerable at times, the water ages for the three representative sites for Case 1 showed substantial uniformity among the three different layers, with a small reduction (approximately 10-30 days) in the middle and bottom layers for R2 due to the effect of outflow (Fig. 11a-c). Compared with the water ages of different layers in the base year (2010), of data obtained for Case 1 did not reveal any distinct discrepancy until the beginning of the stratification in 2010. These findings confirm that the differentiation of water age in the vertical direction was primarily controlled by the thermal stratification. In the early stage of stratification, water age of Case 1 was generally higher than the water age of any layer in 2010, in particular for 

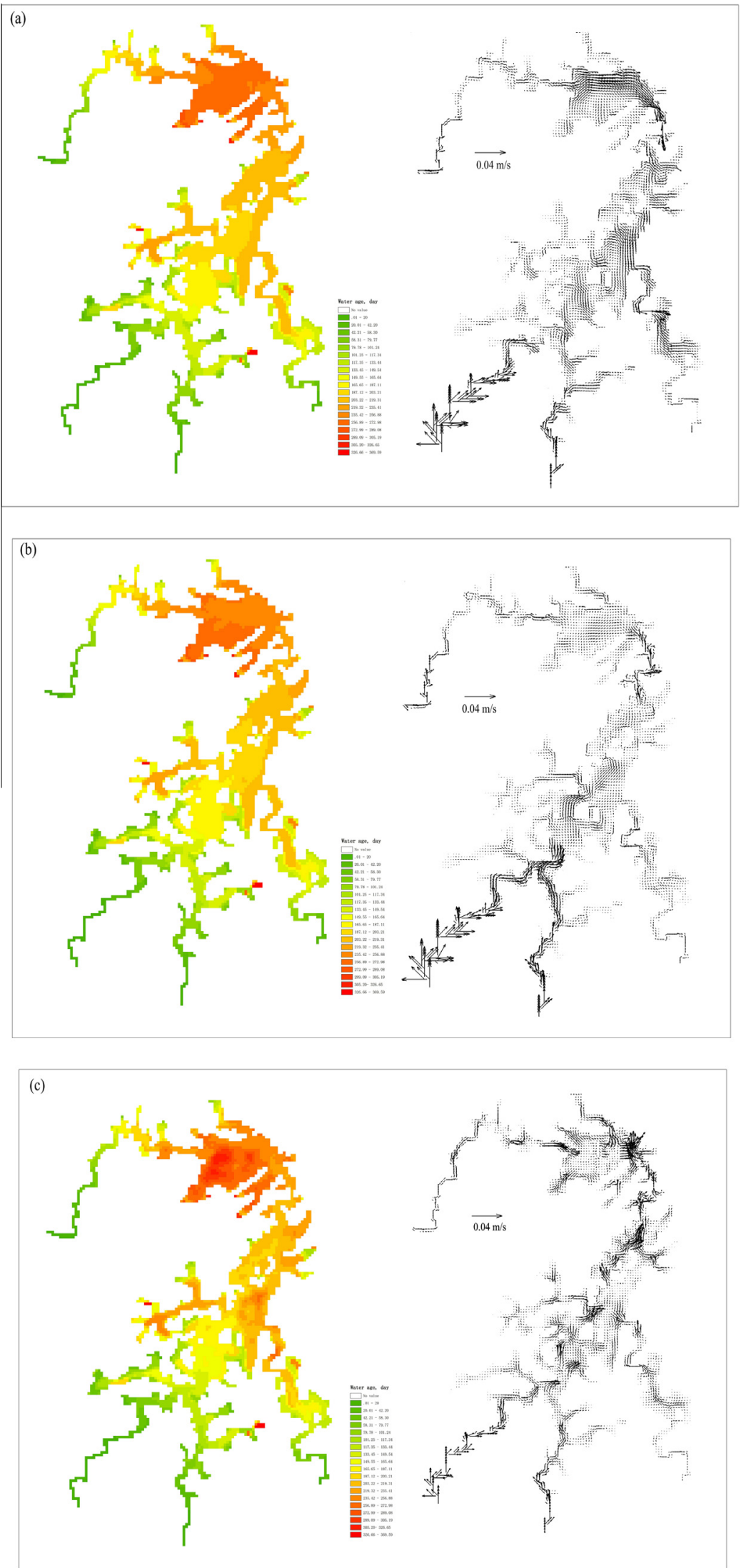

Fig. 12. Spatial distribution of annual average water age and circulation of (a) surface, (b) middle and (c) bottom layers. 

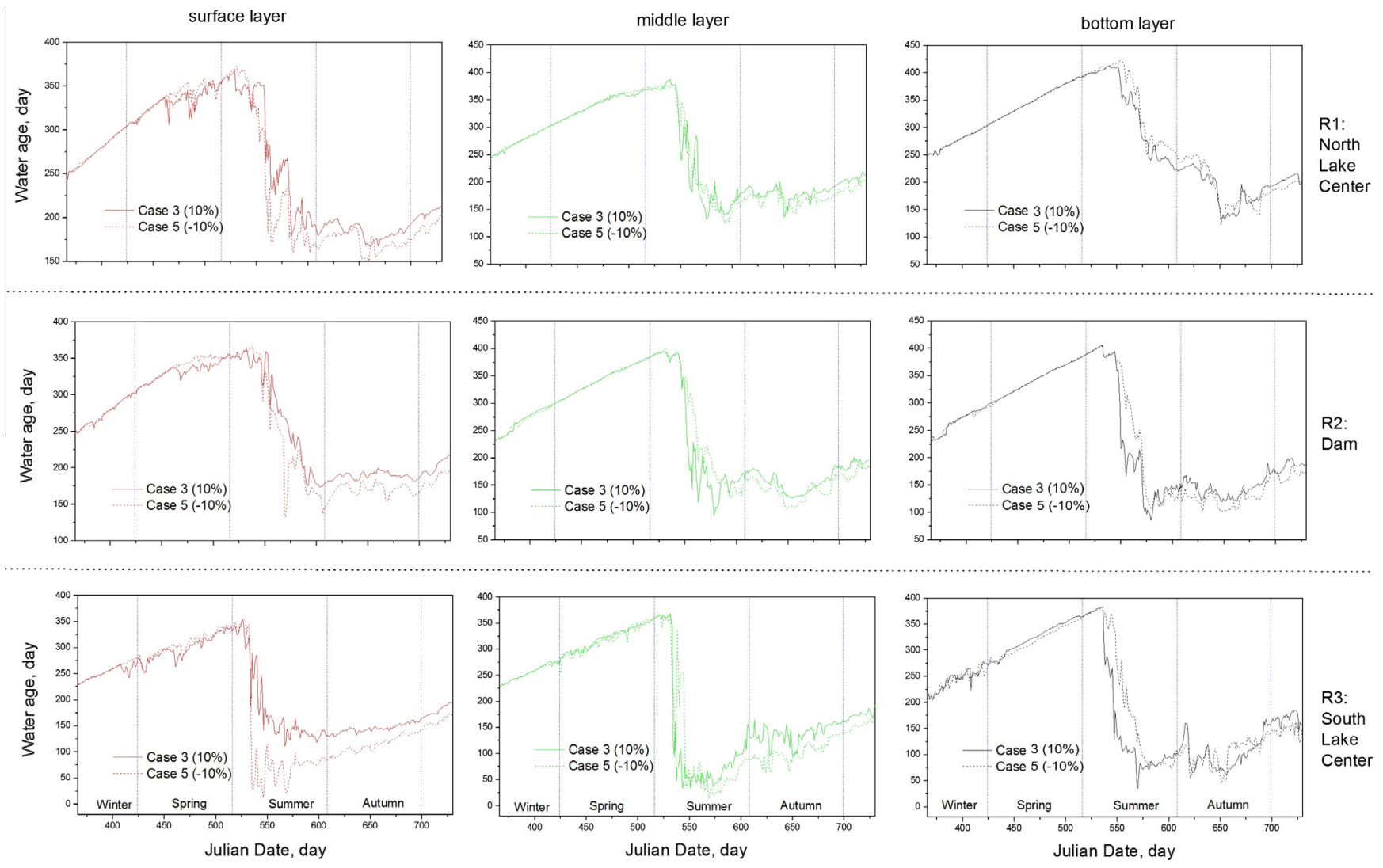

Fig. 13. Comparison of water age of surface, middle and bottom layers at three representative sites in Case 3 and Case 5 in Hongfeng Reservoir.

R1 and R2 sites. However, only R1 retained the higher water age until the end of the year, R2 became close to the water ages in 2010 after the sharp decline in summer, and R3 became smaller after the decline and kept the smaller values to the end. Those results implies that thermal stratification obviously improves the water exchange and pollutant transport in the North Lake, but inhibits that in the South Lake to some extent.

Cases 2-5 were also conducted with approximately 5\%, $10 \%$, $-5 \%$ and $-10 \%$, respectively, higher (positive) or lower (negative) annual average air temperature than that of 2010 to study the impact of thermal stratification on water age. The integral and spatial stability $\left(S_{1}, S_{2}, S_{3}\right.$ and $\left.S_{j}\right)$ generally increased with an increase in the annual average air temperature, particularly, for spring and summer with distinct stratification. Although thermal stratification determined whether the water age stratified, the flow patterns that dominated (overflow, interflow or underflow) in a deep reservoir were attributed to many factors, including the temperature difference between the inflow and the stratified reservoir, inflow/ outflow and outlet depth. The changing annual average air temperature in Cases 2-5 did not reveal a distinct impact on the general flow patterns, which varied with season and position (similar to 2010, results not shown), but affected the water age of different layers. Because the differences of water age among those cases were relatively small, only the results from Case 3 (highest annual average air temperature, 10\% higher than 2010) and Case 5 (lowest annual average air temperature, $10 \%$ lower than 2010) were shown to make the figures more clearly (Fig. 13). Water age was insensitive to the increasing air temperature prior to the occurrence of stratification in the three representative sites. When the stratification began in mid-spring, the water ages of the surface layers of all representative sites slightly decreased with the increase in air temperature (from Case 5 to Case 3). The water ages for the middle and bottom layers remained significantly unchanged (with the exception of a small increase in the bottom layer in R3). It is reasonable since the temperature difference between inflow and the surface layer in the reservoir becomes smaller with increasing air temperature at the early stage of stratification, resulting in less resistance of the overflow, which leads to fast transport and lower water age. When the overflow changed into underflow (R2) or interflow (R1 and R3), the water ages for the surface layers of all of the representative sites in Case 3 increased and exceeded the water age for Case 5. Inversely, the water age for the middle and bottom layers distinctly declined with increasing air temperature, especially for R2 and R3. This might be explained by the decreasing intrusion thickness of interflow or underflow with stronger stratification, leading to a higher velocity and a shorter transport time (Ahlfeld et al., 2003; Zhang et al., 2015). For the balance of the whole system, the slower flow of the surface layer with higher air temperature was also reasonable. At the late stage of stratification (end of summer and early autumn) and the following mixing stage (autumn and winter), the flow transport became slower for all the three layers, with higher water age in Case 3, as the air temperature increased. The reason for this phenomenon needs further study. All results revealed that the increase in air temperature enhanced the stratification stability and the dominated flow (first overflow and then underflow or interflow) in the most time of stratification, but inhibited the transport process of the whole reservoir during the end of the stratification and the mixing stage in Hongfeng Reservoir. These results also indicated the potential relationship between thermal stability and water age.

The results for Cases 2-5 and base year 2010 during summer were employed to quantitatively analyze the impact of thermal stability on water age because the most distinct stratification occurred in summer. Negative linear relationships were found between the average integral stability for the entire reservoir $\left(S_{1}\right.$, $S_{2}$ and $S_{3}$ ) and water age for the outlet of the reservoir (Fig. 14a), 

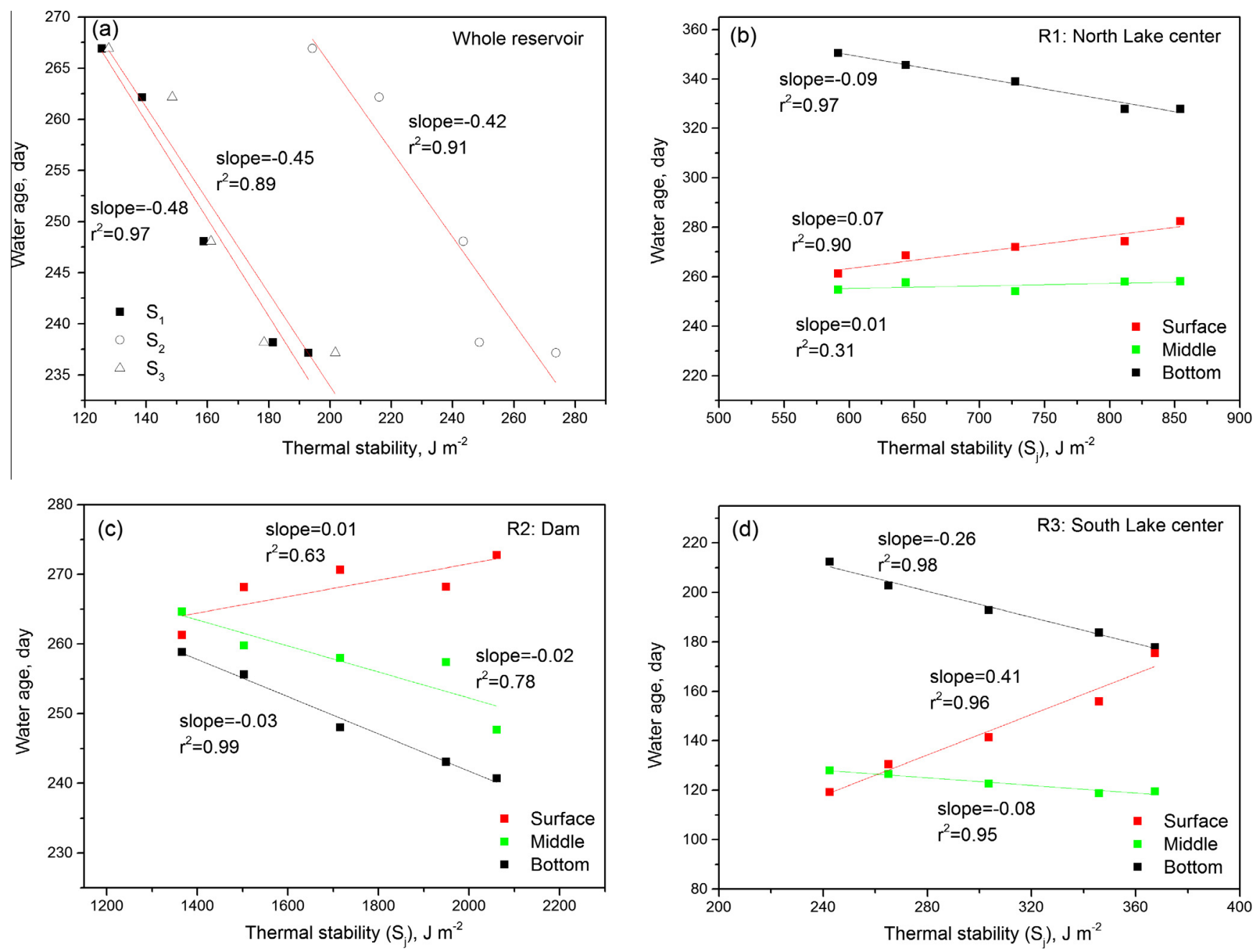

Fig. 14. Relationship between average thermal stability and water age during summer in the whole reservoir and three representative sites.

implying that higher temperature (stronger stratification) generally promotes water exchange in the study reservoir in summer. This was also consistent with the relationships observed for interflow (Ahlfeld et al., 2003; Zhang et al., 2015), which indicates that the flow patterns of Hongfeng Reservoir during summer may be dominated by interflow; however, overflow and underflow appeared at certain times in some areas. Additionally, although $S_{2}$ was much higher than $S_{1}$ and $S_{3}$, the slopes of relationship between stability and water age were very close, implying the consistent effects of stratification (reflected by $S_{1}, S_{2}$ or $S_{3}$ ) on water age. For three representative sites, negative linear relationships were also found between the spatial stability $\left(S_{j}\right)$ of the bottom layers and the corresponding water age during summer, however, positive linear relationships were obtained between the spatial stability $\left(S_{j}\right)$ of the surface layers and the corresponding water age during summer (Fig. 14b-d). On the other hand, the relationships between thermal stability and water age were different for the middle layer, with negative linear relationship for R2 (Dam) and R3 (South Lake Center) sites and positive linear relationship for R1 (North Lake Center) (Fig. 14b-d). Those results revealed that increasing temperature (stratification) in summer distinctly promoted water exchange and pollutant transport in the bottom layers, while inhibited the flow in the surface layers. Moreover, there were some interesting findings for the different effects of increasing air temperature in the middle layers at different sites. The slope (positive or negative) of the middle layer was consistent with the small slope (absolute value) between the surface layer and bottom layer for sites R1 and R3, which might be highly associated with the intrusion depth of inflow. However, the slope of middle layer at site R2 didn't follow the above rule, which might be controlled by the deep dam outflow. More studies are needed for further discussions and better understanding.

\section{Conclusion}

Thermal stratification and pollutant transport processes are significantly related to water quality and algae bloom in deep reservoirs and can be quantified by indicators of Schmidt stability and water age, respectively. In this paper, the original Schmidt stability, which was derived from a one-dimensional assumption, was theoretically extended to a three-dimensional water body and a threedimensional model was calibrated and validated for Hongfeng Reservoir (a deep drinking water reservoir in the Yunnan-Guizhou Plateau of China) based on data from 2009 and 2010. The revised thermal stability and water age characteristics and the controlling factors were discussed based on the representative year (2010). Although the revised stability was similar to the original stability in Hongfeng Reservoir, which exhibited a relatively low level, the greater stratification in other deep water bodies would enhance their difference. Air temperature and water depth were the most important factors for the temporal variation and the spatial 
variation in stability, respectively. The pollutant transport processes in Hongfeng Reservoir were very complex with alternate appearances of overflow, interflow and underflow, depending on the season. A general trend for water age was a gradual increase from south to north in Hongfeng Reservoir with the highest in North Lake, which was consistent with the flow circulations. Although the spatial water age was primarily determined by the morphometry and inflow/outflow, the vertical difference in the water age among the layers was primarily controlled by thermal stratification. The impact of stability on water age was investigated by numerical experiments. Negative linear relationships between the average stability and the water age of the bottom layers in three representative sites during summer were observed, whereas positive linear relationships among the surface layers were observed. Both trends were observed for the middle layers at different sites. These findings provide useful information for a better understanding of the complex hydrodynamic and mass transport processes in a deep reservoir.

\section{Acknowledgments}

This study is supported by the Program for New Century Excellent Talents in University (No. NCET-12-58), the Fundamental Research Funds for the Central Universities (No. 2012LZD10), the Beijing Higher Education Young Elite Teacher Project (No. YETP0275), and the Natural Science Foundation of China (No. 41403113).

\section{References}

Ahlfeld, D., Joaquin, A., Tobiason, J., Mas, D., 2003. Case study: impact of reservoir stratification on interflow travel time. J. Hydraul. Eng. - ASCE 129 (12), 966975.

Ambrosetti, W., Barbanti, L., 2002. Physical limnology of Italian lakes. 2. Relationships between morphometric parameters, stability and Birgean work. J. Limnol. 61, 159-167.

Bai, Z.G., Wan, G.J., Huang, R.G., Liu, T.S., 2002. A comparison on the accumulation characteristics of 7Be and 137Cs in lake sediments and surface soils in western Yunnan and central Guizhou, China. Catena 49, 253-270.

Berntsen, J., 2002. Internal pressure errors in sigma-coordinate ocean models. J. Atmos. Ocean. Technol. 19 (9), 1403-1414.

Boynton, W.R., Garber, J.H., Summers, R., 1995. Inputs, transformations, and transport of nitrogen and phosphorus in Chesapeake Bay and selected tributaries. Estuar. Coasts 18 (1), 285-314.

Chen, X.H., 1992. Prediction of vertical two-dimensional temperature distribution in lakes and reservoirs. J. Wuhan Univ. Hydr. Electr. Eng. 25 (4), 376-383 (in Chinese).

Chen, X.H., Liu, M.N., Lin, Y.S., 1997. Study on two-dimensional water quality distribution in reservoirs. Shui Li Xue Bao 4, 9-16 (in Chinese).

Cheng, W.F., Kao, S.J., 2008. Effects of climate events driven hydrodynamics on dissolved oxygen in a subtropical deep reservoir in Taiwan. Sci. Total Environ. 393, 326-332.

Coats, R., Losada, J.P., Schladow, G., Richards, R., Goldman, C., 2006. The warming of lake Tahoe. Climatic Change 76, 121-148. http://dx.doi.org/10.1007/s10584005-9006-1.

Cole, T.M., Wells, S.A., 2006. CE-QUAL-W2: A Two-dimensional, Laterally Averaged, Hydrodynamic and Water Quality Model, Version 3.5. User's Manual.

Craig, P.M., 2011. User's Manual for EFDC Explorer: A Pre/Post Processor for the Environmental Fluid Dynamics Code. Dynamic Solutions-International, LLC, Knoxville, TN, USA.

Deleersnijder, E., Campin, J.M., Delhez, E.J.M., 2001. The concept of age in marine modelling: I. Theory and preliminary model results. J. Mar. Syst. 28 (3-4), 229267.

Delhez, E.J.M., Campin, J.M., Hirst, A.C., 1999. Toward a general theory of the age in ocean modeling. Ocean Model. 1, 17-27.

Ferris, J.M., Burton, H.R., 1988. The annual cycle of heat content and mechanical stability of hypersaline deep Lake, Vestfold Hills, Antarctica. Hydrobiologia 165, $115-128$.

Gill, A.E., 1982. Atmosphere-Ocean Dynamics. Academic Press, New York, p. 662.

Gu, R., McCutcheon, S.C., Wang, P.F., 1996. Modeling reservoir density underflow and interflow from a chemical spill. Water Resour. Res. 32 (3), 695-705.

Gu, R., Chung, S.W., 1998. Reservoir flow sensitivity to inflow and ambient parameters. J. Water Res. Plann. - ASCE 124 (3), 119-128.

Gu, R., Chung, S.W., 2003. A two-dimensional model for simulating the transport and fate of toxic chemicals in a stratified reservoir. J. Environ. Qual. 32 (2), 620632.
Guo, Y., Zhao, Y.Z., Long, S.X., Li, Y.L., Zhang, B., 2015. Study on water environment characteristics in the stage of goverance effect of lake eutrophication: taking drinking water sources of Hongfeng Reservoir Lake in Guiyang as an example. Environ. Pollut. Control 37 (6), 55-68 (in Chinese).

Hamrick, J.M., 1992. A Three-Dimensional Environmental Fluid Dynamics Computer Code: Theoretical and Computational Aspects. Special Report No. 317 in Applied Marine Science and Ocean Engineering. College of William and Mary, Virginia Institute of Marine Science.

Hamrick, J.M., 1994. Application of the EFDC, Environmental Fluid Dynamics Computer Code to SFWMD Water Conservation Area 2A. South Florida Water Management District, West Palm Beach, FL, pp. 1-126.

Hein, T., Baranyi, C., Reckendorfer, W., Schiemer, F., 2004. The impact of surface water exchange on the nutrient and particle dynamics in side-arms along the River Danube, Austria. Sci. Total Environ. 328, 207-218.

Holzner, C.P., Aeschbach-Hertig, W., Simona, M., Veronesi, M., Imboden, D.M., Kipfer, R., 2009. Exceptional mixing events in meromictic Lake Lugano (Switzerland/Italy), studied using environmental tracers. Limnol. Oceanogr. 54, 1113-1124.

HydroQual Inc., 2002. A Primer for ECOMSED, Version 1.3, User's Manual. HydroQual Inc., Lethbridge Plaza, Mahwah, NJ.

Idso, S.B., 1973. On the concept of lake stability. Limnol. Oceanogr. 18, 681-683.

Ito, Y., Momii, K., 2015. Impacts of regional warming on long-term hypolimnetic anoxia and dissolved oxygen concentration in a deep lake. Hydrol. Processes 29, 2232-2242. http://dx.doi.org/10.1002/hyp.10362.

Ji, Z.G., Morton, M.R., Hamrick, J.M., 2001. Wetting and drying simulation of estuarine processes. Estuar. Coast. Shelf Sci. 53 (5), 683-700.

Jiang, C.L., Zhu, L.Q., Hu, X.Q., 2010. Reasons and control of eutrophication in new reservoirs. In: Ansari, A.A., Singh, G.S., Lanza, G.R. (Eds.), Eutrophication: Causes, Consequences and Control. Springer, Dordrecht, The Netherlands, pp. 325-340.

Kling, G.W., 1988. Comparative transparency, depth of mixing, and stability of stratification in Lakes of Cameroon, West Africa. Limnol. Oceanogr. 33, $27-40$.

Li, Y.P., Acharya, K., Yu, Z.B., 2011. Modeling impacts of Yangtze River water transfer on water ages in Lake Taihu, China. Ecol. Eng. 37, 325-334.

Liu, X.H., Huang, W.R., 2009. Modeling sediment resuspension and transport induced by storm wind in Apalachicola Bay, USA. Environ. Model. Software 24 (11), 1302-1313.

Liu, Z., Wang, H.Y., Guo, X.Y., 2012. The age of Yellow river water in the Bohai Sea. J. Geophys. Res. 117, C11006.

Lucas, L.V., Thompson, J.K., Brown, L.R., 2009. Why are diverse relationships observed between phytoplankton biomass and transport time? Limnol. Oceanogr. 54, 381-390.

Mellor, G.L., Yamada, T., 1982. Development of a turbulence closure model for geophysical fluid problems. Rev. Geophys. 20 (4), 851-875.

Minns, C.K., Moore, J.E., Doka, S.E., John, M.A.St., 2011. Temporal trends and spatial patterns in the temperature and oxygen regimes in the Bay of Quinte, Lake Ontario, 1972-2008. Aquat. Ecosyst. Health 14, 9-20. http://dx.doi.org/10.1080/ 14634988.2011 .547327$.

Nõges, P., Nõges, T., Ghiani, M., Paracchini, B., Grande, J.P., Sena, F., 2011 Morphometry and trophic state modify the thermal response of lakes to meteorological forcing. Hydrobiologia 667, 241-254. http://dx.doi.org/10.1007/ s10750-011-0691-7.

Read, J.S., Hamilton, D.P., Jones, I.D., Muraoka, K., Winslow, L.A., Kroiss, R., Wu, C.H., Gaiser, E., 2011. Derivation of lake mixing and stratification indices from high-resolution lake buoy data. Environ. Modell. Software 26, 13251336.

Rolland, D.C., Bourget, S., Warren, A., Laurion, I., Vincent, W.F., 2013. Extreme variability of cyanobacterial blooms in an urban drinking water supply. J. Plankton Res. 35, 744-758. http://dx.doi.org/10.1093/plankt/fbt042.

Schmidt, W., 1928. Über Temperatur and Stabilitätsverhaltnisse von Seen. Geograph. Annaler 10, 145-177.

Shang, L.H., Li, Q.H., Qiu, H.B., Qiu, G.L., Xin, X.B., 2011. Chlorophyll-a distribution and phosphorus cycle in water body of Hongfeng Reservoir, Guizhou. Chin. J. Ecol. 30 (5), 1023-1030 (in Chinese).

Shen, J., Wang, H.V., 2007. Determining the age of water and long-term transport timescale of the Chesapeake Bay. Estuar. Coast. Shelf Sci. 74, 585-598.

Shen, Y.M., Wang, J.H., Zheng, B.H., 2011. Modeling study of residence time and water age in Dahuofang Reservoir in China. Sci. China Phys. Mech. Astron. 54 (1), 127-142.

Smagorinsky, J., 1963. General circulation experiments with the primitive equations: the basic experiment. Mon. Weather Rev. 91 (3), 99-164.

Straile, D., Kerimoglu, O., Peeters, F., Jochimsen, M.C., Mmerlinw, R.K., Rinke, K., Rothhaupt, K.O., 2010. Effects of a half a millennium winter on a deep lake - a shape of things to come? Global Change Biol. 16, 2844-2856. http://dx.doi.org/ 10.1111/j.1365-2486.2009.02158.x.

Straskraba, M., Tundisi, J.G., Duncan, A., 1999. Comparative Reservoir Limnology and Water Quality Management. Kluwer Academic Publishers, Dordrecht, The Netherlands.

Takeoka, H., 1984. Fundamental concepts of exchange and transport time scales in a coastal sea. Cont. Shelf Res. 3 (3), 322-326.

Valerio, G., Pilotti, M., Barontini1, S., Leoni, B., 2015. Sensitivity of the multiannual thermal dynamics of a deep pre-alpine lake to climatic change. Hydrol. Process. 29, 767-779. http://dx.doi.org/10.1002/hyp.10183.

Vinçon-Leite, B., Lemaire, B.J., Khac, V.T., Tassin, B., 2014. Long-term temperature evolution in a deep sub-alpine lake, Lake Bourget, France: how a onedimensional model improves its trend assessment. Hydrobiologia 731, 49-64. http://dx.doi.org/10.1007/s10750-014-1818-4. 
Wang, S., Qian, X., Han, B.P., Luo, L.C., Hamilton, D.P., 2012a. Effects of local climate and hydrological conditions on the thermal regime of a reservoir at Tropic of Cancer, in southern China. Water Res. 46, 2591-2604.

Wang, J.F., Chen, J.A., Yang, Y.Q., Xia, P.H., Yang, H.Q., 2012b. Physical and chemical characteristics of water in Lake Hongfeng during the disappearance of seasonal stratification. Res. Environ. Sci. 25 (8), 845-851 (in Chinese).

Wagner, C., Adrian, R., 2009. Cyanobacteria dominance: quantifying the effects of climate change. Limnol. Oceanogr. 54, 2460-2468.

Winder, M., Schindler, D.E., 2004. Climate change uncouples trophic interactions in an aquatic ecosystem. Ecology 85, 2100-2106.

Wu, G.Z., Xu, Z.X., 2011. Prediction of algal blooming using EFDC model: case study in the Daoxiang Lake. Ecol. Model. 222, 1245-1252. http://dx.doi.org/10.1016/j. ecolmodel. 2010.12.021.

Wu, B.B., Wang, G.Q., Liu, C.M., Xu, Z.X., 2013. Modeling impacts of highly regulated inflow on thermal regime and water age in a shallow reservoir. J. Hydroinform. 15 (4), 1312-1325.
Yang, Z.J., Liu, D.F., Ji, D.B., Xiao, S.B., 2010. Influence of the impounding process of the three Gorges Reservoir up to water level $172.5 \mathrm{~m}$ on water eutrophication in the Xiangxi Bay. Sci. China (Technol. Sci.) 53, 1114-1125.

Yu, H., Tsuno, H., Hidaka, T., Jiao, C.M., 2010. Chemical and thermal stratification in lakes. Limnology 11, 251-257. http://dx.doi.org/10.1007/ s10201-010-0310-8

Zhang, X.F., Ren, S., Lu, J.Q., Lu, X.H., 2015. Effect of thermal stratification on interflow travel time in stratified reservoir. J. Zhejiang Univ. - Sci. A (Appl. Phys. Eng.) 16 (4), 265-278.

Zou, R., Carter, S., Shoemaker, L., Parker, A., Henry, T., 2006. Integrated hydrodynamic and water quality modeling system to support nutrient total maximum daily load development for Wissahickon Creek, Pennsylvania. J. Environ. Eng. 132 (4), 555-566. 